CAIO RAFAEL DO NASCIMENTO SANTIAGO

Desenvolvimento de um ambiente de computação voluntária baseado em computação ponto-a-ponto

São Paulo

2015 


\section{Desenvolvimento de um ambiente de computação voluntária baseado em computação ponto-a-ponto}

Versão corrigida

Dissertação apresentada à Escola de Artes, Ciências e Humanidades da Universidade de São Paulo para obtenção do título de Mestre em Ciências pelo Programa de Pós-graduação em Sistemas de Informação.

Área de Concentração: Sistemas de Informação

Versão corrigida contendo as alterações solicitadas pela comissão julgadora em 13 de Março de 2015. A versão original encontra-se em acervo reservado na Biblioteca da EACH-USP e na Biblioteca Digital de Teses e Dissertações da USP (BDTD), de acordo com a Resolução CoPGr 6018, de 13 de outubro de 2011.

Orientador: Prof. Dr. Luciano Antonio Digiampietri

São Paulo 
Autorizo a reprodução e divulgação total ou parcial deste trabalho, por qualquer meio convencional ou eletrônico, para fins de estudo e pesquisa, desde que citada a fonte.

Santiago, Caio Rafael do Nascimento

Desenvolvimento de um ambiente de computação voluntária baseado em computação ponto-a-ponto / Caio Rafael do Nascimento Santiago ; orientador, Luciano Antonio Digiampietri.

- São Paulo, 2015 $70 \mathrm{f}$ : : il.

Dissertação (Mestrado em Ciências) - Programa de PósGraduação em Sistemas de Informação, Escola de Artes, Ciências e Humanidades, Universidade de São Paulo Versão corrigida

1. Sistemas colaborativos. 2. Redes de computadores.

3. Sistemas distribuídos. 4. Pesquisa científica. I.

Digiampietri, Luciano Antonio, orient. II. Título. 
Dissertação de autoria de Caio Rafael do Nascimento Santiago, sob o título "Desenvolvimento de um ambiente de computação voluntária baseado em computação ponto-a-ponto", apresentada à Escola de Artes, Ciências e Humanidades da Universidade de São Paulo, para obtenção do título de Mestre em Ciências pelo Programa de Pósgraduação em Sistemas de Informação, na área de concentração Sistemas de Informação, aprovada em 13 de Março de 2015 pela comissão julgadora constituída pelos doutores:

Prof. Dr. Luciano Antonio Digiampietri

Presidente

Instituição: Escola de Artes, Ciências e Humanidades - USP

Prof. Dr. João Eduardo Ferreira

Instituição: Instituto de Matemática e Estatística

Prof. Dr. Marcos Lordello Chaim

Instituição: Escola de Artes, Ciências e Humanidades - USP 
Dedico este trabalho a minha mãe por todo o apoio e compreensão, sem os quais não seria possivel alcançar o que alcancei. 


\section{Agradecimentos}

Agradeço antes de mais nada a minha mãe Sandra por todo o esforço, dedicação, e principalmente pela compreensão que foram fundamentais para enfrentar os desafios que me trouxeram até aqui.

Ao meu orientador, Prof. Dr. Luciano Antonio Digiampietri, por ter me guiado no decorrer deste trabalho, e sem o qual nada disso seria possível.

A minha namorada Karen por todos os momentos de felicidade que fizeram esta jornada não parecer tão longa.

Aos bons amigos que a tantos anos me acompanham, sejam eles na faculdade ou fora dela, por todos os momentos de descontração que dão folego para trilhar essa jornada.

A todos os professores da EACH-USP da graduação e da pós-graduação pela contribuição na minha formação.

A Fapesp pelo apoio financeiro (projetos 2013/07935-5 e 2009/10413-5). 
"O aspecto mais triste da vida de hoje é que a ciência ganha em conhecimento mais rapidamente que a sociedade em sabedoria."

(Isaac Asimov) 


\section{Resumo}

SANTIAGO, Caio Rafael do Nascimento. Desenvolvimento de um ambiente de computação voluntária baseado em computação ponto-a-ponto. 2015. 70 f. Dissertação (Mestrado em Ciências) - Escola de Artes, Ciências e Humanidades, Universidade de São Paulo, São Paulo, 2015.

As necessidades computacionais de experimentos científicos muitas vezes exigem computadores potentes. Uma forma alternativa de obter esse processamento é aproveitar o processamento ocioso de computadores pessoais de modo voluntário. Essa técnica é conhecida como computação voluntária e possui grande potencial na ajuda aos cientistas. No entanto existem diversos fatores que podem reduzir sua eficiência quando aplicada a experimentos científicos complexos, por exemplo, aqueles que envolvem processamento de longa duração, uso de dados de entrada ou saída muito grandes, etc. Na tentativa de solucionar alguns desses problemas surgiram abordagens que aplicam conceitos de computação ponto-a-ponto. Neste projeto foram especificados, desenvolvidos e testados um ambiente e um escalonador de atividades que aplicam conceitos de computação pontoa-ponto à execução de workflows com computação voluntária. Quando comparado com a execução local de atividades e com a computação voluntária tradicional houve melhoras em relação ao tempo de execução (até $22 \%$ de redução quando comparada com a computação voluntária tradicional nos testes mais complexos) e em alguns casos também houve uma redução no consumo de banda de upload do servidor de até $62 \%$.

Palavras-chave: Computação Voluntária; Desktop Grid; Ponto-a-Ponto; Escalonamento 


\begin{abstract}
SANTIAGO, Caio Rafael do Nascimento. Development of an volunteer computing environment based in peer-to-peer computing. 2015. 70 p. Dissertation (Master of Science) - School of Arts, Sciences and Humanities, University of São Paulo, São Paulo, 2015 .

The computational needs of scientific experiments often require powerful computers. One alternative way to obtain this processing power is taking advantage of the idle processing of personal computers as volunteers. This technique is known as volunteer computing and has great potential in helping scientists. However, there are several issues which can reduce the efficiency of this approach when applied to complex scientific experiments, such as, the ones with long processing time, very large input or output data, etc. In an attempt to solve these problems some approaches based on $\mathrm{P} 2 \mathrm{P}$ concepts arisen. In this project a workflow execution environment and a scheduler of activities were specified, developed and tested applying P2P concepts in the workflows execution using volunteer computing. When compared with the local execution of activities and traditional volunteer computing was the execution time was improved (until $22 \%$ of reduction when compared with the traditional volunteer computing in the most complex tests) and in some cases there was also a reduction of the server upload bandwidth use of until $62 \%$.
\end{abstract}

Keywords: Volunteer Computing; Desktop Grid; Peer-to-Peer; Scheduling 


\section{Lista de figuras}

Figura 1 - Estruturas básicas de workflows . . . . . . . . . . . . . 23

Figura 2 - Arquitetura do projeto Jovem Pesquisador . . . . . . . . . . . . . 25

Figura 3 - Diagrama de classes da estrutura de representação do workflow . . . 37

Figura 4 - Diagrama de classes da estrutura modificada de representação do workflow 37

Figura 5 - Diagrama de classes da estrutura do executor Workflow . . . . . . . . 38

Figura 6 - Diagrama de classes da estrutura modificada do executor Workflow . . 39

Figura 7 - Diagrama de classes da estrutura de comunicação entre o servidor e os voluntários . . . . . . . . . . . . . . . . . . . . . 39

Figura 8 - Workflow de teste baseado em um problema real de análise de redes sociais .......................... . . . 47

Figura 9 - Utilização do processamento dos testes baseados em um problema real de análise de redes sociais . . . . . . . . . . . . . . . 53

Figura 10 - Processamento em função do tempo (segundos) de cada voluntário no caso de exemplos simplificados (com uma estrutura) . . . . . . . . . . 55 


\section{Lista de algoritmos}

Algoritmo 1 - Algoritmo de Computação Voluntária aplicando técnicas de P2P - Funcionamento do algoritmo no voluntário . . . . . . . . . . . . . . . . . . 42

Algoritmo 2 - Escolha da melhor atividade para se processar . . . . . . . . . . . . . 43 


\section{Lista de tabelas}

Tabela 1 - Dados extraídos dos artigos referentes à estrutura de dados . . . . . . . 28

Tabela 2 - Dados extraídos dos artigos referentes à avaliação do escalonamento . . 32

Tabela 3 - Configurações do computadores utilizados . . . . . . . . . . . . . 45

Tabela 4 - Tempo de duração do processamento dos casos de testes reais de análise de redes sociais . . . . . . . . . . . . . . . . . 50

Tabela 5 - Tempo médio de espera transferindo dados nos voluntários nos casos de teste de análise de redes sociais . . . . . . . . . . . . . . . 51

Tabela 6 - Dados transferidos por cada voluntário em MBs no caso real de redes

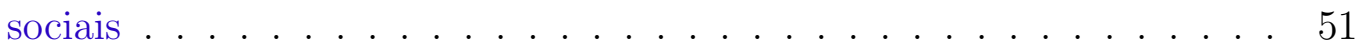

Tabela 7 - Dados transferidos por cada voluntário em MBs no caso real de redes sociais sem a execução de atividades no servidor (com redundância) . . 52

Tabela 8 - Tempo de duração do processamento dos casos de testes exemplos simplificados (com uma estrutura) . . . . . . . . . . . . 54

Tabela 9 - Dados transferidos por cada voluntário em MBs no caso de exemplos simplificados (com uma estrutura) . . . . . . . . . . . . 56 56

Tabela 10 - Tempo de duração do processamento dos casos de testes exemplos simplificados (com 10 estruturas) . . . . . . . . . . . . 56

Tabela 11 - Tempo médio de espera transferindo dados pelos voluntários nos casos de exemplos simplificados (com 10 estruturas) . . . . . . . . . . . 57

Tabela 12 - Dados transferidos por cada voluntário em MBs no caso de exemplos simplificados (com 10 estruturas) . . . . . . . . . . . . . 58

Tabela 13 - Tempo de duração do processamento dos casos de testes exemplos simplificados (com 10 estruturas e redundância $) \ldots . . .58$

Tabela 14 - Comparação entre o tempo de CV com o tempo da CV com P2P (com e sem redundância -10 estruturas $)$. . . . . . . . . . . . 59

Tabela 15 - Dados transferidos por cada voluntário em MBs no caso de exemplos simplificados (com 10 estruturas e redundância) . . . . . . . . . . . . 59 


\section{Sumário}

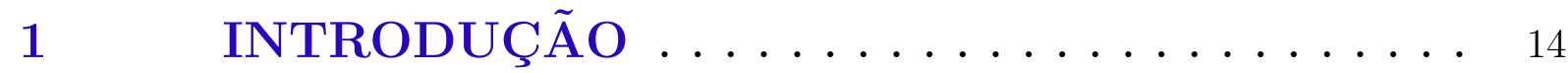



$1.2 \quad$ Metodologia ...................... 15

1.3 Resultados Obtidos . . . . . . . . . . . . . . 16

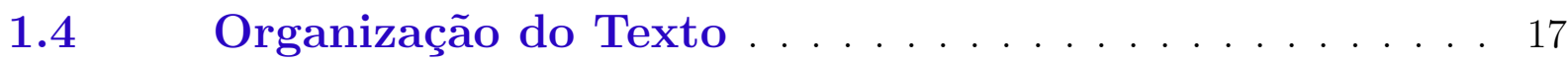

2 CONCEITOS FUNDAMENTAIS . . . . . . . . 19

$2.1 \quad$ Workflows Científicos . . . . . . . . . . . . . 19

2.2 Computação Voluntária . . . . . . . . . . . . . 20

$2.3 \quad$ Desktop Grids . . . . . . . . . . . . . . . 21

2.4 Composição de Serviços . . . . . . . . . . . . 21



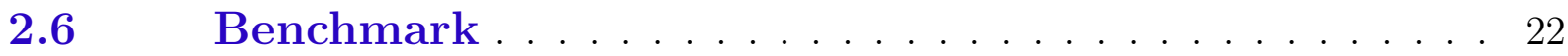



2.8 Considerações Finais . . . . . . . . . . . . . . 26



3.1 Resumo da Revisão . . . . . . . . . . . . . . . 27

3.1.1 Estrutura de dados . . . . . . . . . . . . . 27

3.1.2 Algoritmo de escalonamento . . . . . . . . . . . 30

3.1.3 Avaliação do escalonamento . . . . . . . . . . . . 31

3.2 Comparação com a Solução Desenvolvida no Mestrado 34

3.3 Considerações Finais . . . . . . . . . . . . . . 35

4 SOLUÇÃO DESENVOLVIDA $\ldots \ldots \ldots \ldots \ldots$

4.1 Extensão do Modelo de Representação de Workflows . 36

4.2 Comunicação entre Computadores . . . . . . . . . . 39

4.3 Computação Voluntária aplicando técnicas de Pontoa-Ponto . . . . . . . . . . . . . . . . . . 41

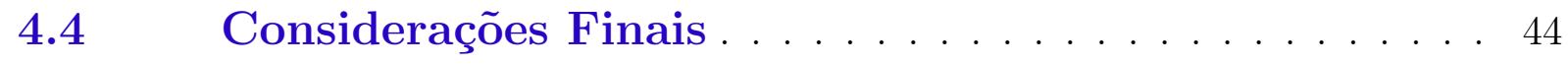


5.1 Avaliação da Solução . . . . . . . . . . . . . . 45

5.1.1 Caso de Teste Baseado em Análise de Redes Sociais . . . 46

5.1.2 Caso de Teste Baseado em Exemplos Simplificados . . . . 48

$5.2 \quad$ Resultados . . . . . . . . . . . . . . . . . . . . 49

5.2.1 Caso de Teste Baseado em Análise de Rede Sociais . . . . 49

5.2.2 Caso de Teste Baseado em Exemplos Simplificados . . . . 53

$5.3 \quad$ Considerações Finais . . . . . . . . . . . . . . . 59

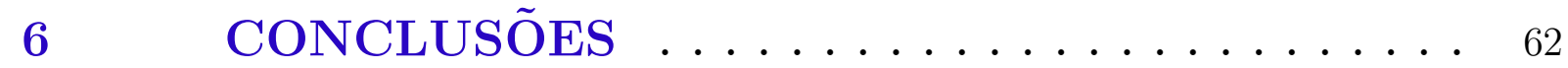



6.2 Trabalhos Futuros . . . . . . . . . . . . . . . 64

$\operatorname{Referências~}^{1} \ldots \ldots \ldots \ldots \ldots \ldots$ 


\section{INTRODUÇÃO}

As necessidades computacionais de experimentos científicos muitas vezes exigem computadores potentes, que em geral são caros e que, potencialmente, ficarão ociosos em boa parte do tempo (MUTKA; LIVNY, 1991; ACHARYA; EDJLALI; SALTZ, 1997). Por outro lado, o avanço dos computadores pessoais, com CPUs multinúcleos e GPUs, tipicamente atendem às necessidades de seus usuários com facilidade. Portanto temos uma situação na qual computadores pessoais passam a maior parte do tempo ociosos e computadores científicos sobrecarregados durante períodos de pico de experimentos.

Experimentos científicos muitas vezes são modelados como workflows científicos (MEDEIROS et al., 1996), que por si só já possuem uma grande capacidade de paralelização. Em geral, um workflow científico é executado em um único computador, que não é necessariamente muito potente, ou em um grid, que exige recursos e planejamento. Uma recente abordagem para aproveitar o poder dos workflows é utilizar vários computadores pessoais, como por exemplo desktop grids (KONDO et al., 2007; ANDERSON, 2004) ou computação voluntária (ANDERSON; FEDAK, 2006).

A computação voluntária (CV) tenta aproveitar o recurso ocioso "doando-o" para um determinado projeto, isto é, o responsável pelo projeto transmite (geralmente via internet) para outro computador (doador) uma atividade para que este a processe. Esse paradigma tem o poder de fornecer muito processamento (ANDERSON, 2004), mas quando se trata de experimentos científicos existem muitos fatores que podem tornar esta solução pouco eficiente, como por exemplo, processamento de longa duração (DETHIER et al., 2008), grande volume de dados (DUAN et al., 2012), heterogenia de sistemas (DORNEMANN et al., 2012) e instabilidade dos computadores voluntários (DIAS et al., 2010).

No intuito de resolver algumas destas questões surgiram propostas que empregam conceitos de computação ponto-a-ponto (P2P) (MAJITHIA et al., 2004; ZHOU; LO, 2006; ZHAO; YANG; XU, 2009) em workflows que utilizam processamento voluntário. Esta é uma solução bastante dinâmica e que, portanto, é capaz de lidar com ambientes heterogêneos e ser tolerante a falhas, além de minimizar ou ao menos descentralizar o tráfego de dados. Pode-se encarar esse conceito como uma extensão da coreografia de serviços (PELTZ, 2003).

A arquitetura tradicional de computação voluntária se assemelha a execução tradicional de serviços web (web services). A composição de forma descentralizada de serviços 
web, na qual os serviços se comunicam diretamente entre si (ponto-a-ponto) possibilitou melhorias significativas em termos de escalabilidade e transferência de dados (DUAN et al., 2012).

Este projeto visa a ajudar a enfrentar os desafios de escalonar tarefas em workflows científicos em uma arquitetura descentralizada P2P utilizando-se computação voluntária.

\section{$1.1 \quad$ Objetivos}

O objetivo geral deste projeto é verificar se a aplicação de técnicas ponto-a-ponto (P2P) em ambientes de computação voluntária (CV) pode acarretar em uma melhora no desempenho, quando comparada com a computação voluntária tradicional.

Para alcançar esse objetivo os seguintes objetivos específicos foram estabelecidos:

- Construir/expandir um Sistema de Gerenciamento de Workflows (SGW) de fácil modularização e expansão, com o intuito de desenvolver diversos ambientes de execução de workflows capazes de trabalhar com diferentes algoritmos de escalonamento. $\mathrm{O}$ SGW resultante deve ser o mais transparente possível para o projetista do workflow, não sendo necessário conhecimento sobre os computadores participantes do sistema e nem sobre a estrutura de rede na qual se comunicam;

- Desenvolver um ambiente de computação voluntária;

- Especificar e desenvolver um ambiente de computação voluntária que aplique técnicas $\mathrm{P} 2 \mathrm{P}$

- Avaliar o desempenho do ambiente proposto quando comparado com a computação voluntária tradicional e com a execução local de workflows;

- Analisar os resultados da avaliação.

\section{$1.2 \quad$ Metodologia}

A metodologia deste trabalho foi iniciada com a realização de um estudo teórico a fim de verificar o que já havia sido feito na literatura correlata e estudar a viabilidade deste trabalho. Para este fim foi feita uma revisão sistemática para englobar o principal tópico deste trabalho: algoritmos de escalonamento em workflows científicos que apliquem técnicas 
de P2P. A revisão indicou que a literatura correlata se mostrou escassa, corroborando com a contribuição potencial deste projeto.

Em seguida foi estendido um Sistema de Gerenciamento de Workflows (SGW) de forma a possibilitar a construção de estruturas para o escalonamento de workflows que fosse flexível o suficiente para utilizar diferentes tipos de técnicas de escalonamento. Para isto, este trabalho utilizou e expandiu o SGW desenvolvido no projeto Jovem Pesquisador em Centros Emergentes - FAPESP do orientador, intitulado "Gerenciamento e Composição Automática de Serviços Web Semânticos" (DIGIAMPIETRI et al., 2011; DIGIAMPIETRI et al., 2013; ZUNIGA et al., 2014).

A partir do SGW existente foram desenvolvidos três métodos de escalonamento de workflows. O primeiro método foi um método de execução local, envolvendo apenas um computador, baseado no Método do Caminho Crítico, no qual o workflow é visto como um dígrafo e prioriza-se o caminho mais longo. O segundo método é a computação voluntária tradicional, em que não há a interação entre computadores voluntários. O terceiro é um método de computação voluntária aplicando técnicas de computação P2P, e é de fato o principal objetivo deste trabalho. Os dois primeiros métodos têm duas funções neste trabalho: servem como base para o desenvolvido do terceiro método, pois seus códigos são parcialmente reutilizados; e contribuem para a avaliação do desempenho do terceiro método.

A avaliação do desempenho da solução desenvolvida foi realizada pela comparação com a computação voluntária tradicional e a execução local, a partir de diferentes métricas aplicadas aos resultados obtidos em dois cenários de testes. No primeiro cenário são utilizados exemplos simplificados (toy examples) baseados nas estruturas básicas de workflow (BHARATHI et al., 2008). Neste cenário, cada estrutura é confrontada com situações de alta transferência dados e processamento de longa duração. O segundo cenário é um caso de teste real da área de análise de redes sociais.

\subsection{Resultados Obtidos}

Os resultados iniciais obtidos na avaliação da solução desenvolvida foram bastante promissores, quando comparado com a execução local de atividades e com a computação voluntária tradicional. Ao todo foram utilizados quatro computadores na infraestruturas de testes, estes processaram dois casos de teste: um caso de testes real envolvendo análise de 
redes sociais; e um caso envolvendo exemplos simplificados utilizando diferentes estruturas básicas de workflows(BHARATHI et al., 2008).

O tempo total de execução foi reduzido em comparação com a computação voluntária, tanto no caso de redes sociais (entre 3,5\% e 36\% de redução) quanto no caso de exemplos simplificados com complexos (entre 13\% e 26\% de redução). Apenas em alguns casos com exemplos simplificados a execução local foi a mais rápida.

Um fator para a diminuição no tempo de execução foi a diminuição do tempo que os voluntários ficam esperando com transferências de dados. O caso de redes sociais apresentou uma redução de até $31 \%$ e o caso dos exemplos simplificados apresentou uma redução de até $63 \%$.

Quanto ao consumo de banda de upload do servidor, a computação voluntária tradicional se mostrou melhor no caso de análise de redes sociais quando desconsiderada a redundância (de $43 \%$ a $53 \%$ melhor). A situação se inverte quando considerada a redundância e a solução desenvolvida se mostrou $36 \%$ melhor. Nos outros casos a solução desenvolvida se mostrou equivalente ou melhor chegando a $62 \%$ melhor sem redundância e $79 \%$ com redundância.

\subsection{Organização do Texto}

Esta dissertação está dividida em seis capítulos, incluindo esta introdução. Os demais capítulos estão organizados da seguinte forma:

- O Capítulo 2 contém um resumo de alguns conceitos teóricos pertinentes para o entendimento deste trabalho. Estes conceitos envolvem principalmente a computação voluntária, os elementos da organização de workflows e os conceitos de composição de serviços que inspiraram a solução desenvolvida.

- O Capítulo 3 sumariza a revisão sistemática realizada abordando soluções similares, isto é, sistema de computação voluntária com elementos presentes de P2P.

- O Capítulo 4 descreve a solução especificada e desenvolvida, detalhando tanto os aspectos do servidor quanto dos voluntários, bem como descrevendo a forma como eles se comunicam. Além disso, também é descrito como foi estruturado e estendido o SGW que serviu de base para o resto do desenvolvimento. Por fim, esse capítulo 
também apresenta os outros métodos de escalonamento (utilizados para comparação de desempenho), com um enfoque principalmente na organização dos computadores. - O Capítulo 5 descreve como a solução foi avaliada, isto é, como os métodos de escalonamento foram comparados, os cenários de testes e as formas de execução. Além disso, neste capítulo os resultados destas comparações são apresentados e discutidos a partir de algumas métricas.

- Finalmente, o Capítulo 6 apresenta as considerações finais sobre este trabalho, onde são expostas as contribuições alcançadas, assim como possíveis melhorias e trabalhos futuros. 


\section{CONCEITOS FUNDAMENTAIS}

Neste capítulo são descritos os conceitos fundamentais acerca do trabalho, os quais serão utilizados como base ao longo desta dissertação. Estes conceitos envolvem principalmente a computação voluntária, os elementos da organização de workflows e os conceitos de composição de serviços que inspiraram a solução desenvolvida.

\subsection{Workflows Científicos}

Workflows (ou fluxos de trabalho) podem ser definidos como modelos de representação e execução de um conjunto de atividades a serem executadas de forma coordenada. Essa estrutura concede um alto poder de representação e paralelização, portanto são muito úteis e amplamente utilizados, especialmente, em sistemas distribuídos. Os workflows podem variar muito em forma, espécie ou propósito, e uma das diversas maneiras de classifica-los é a divisão entre workflows corporativos (ou de negócios) e científicos.

A natureza dos workflows científicos é bastante diferente dos workflows corporativos (MEDEIROS et al., 1996; TAYLOR et al., 2007). Tipicamente, workflows corporativos se dedicam mais a armazenar objetivos e manipulá-los conforme regras predefinidas, enquanto que workflows científicos enfocam na transferência e manipulação de dados. O volume de dados costuma ser significativamente maior nos workflows científicos e, embora ambos possuam atividades de longa duração, nos workflows corporativos o tempo costuma ser determinado pela interação dos participantes com o workflow, diferente dos workflows científicos em que o tempo é determinado pelo processamento pesado das atividades que o compõem.

Os workflows científicos tendem a ser mais complexos e dinâmicos e, por serem projetados por cientistas, precisam adequar-se às necessidades de experimentos científicos com naturezas diversas. Por esse motivo é comum terem que lidar com ambientes heterogêneos, mesclando diferentes tecnologias, por exemplo, combinando execuções locais com execuções remotas de tarefas.

A solução desenvolvida no decorrer deste trabalho se propõe a lidar apenas com workflows científicos, portanto não serão analisados e discutidos workflows corporativos. Os problemas com os quais a solução desenvolvida foi confrontada são aqueles focados em workflows científicos, como transferência e processamento de dados. 


\subsection{Computação Voluntária}

A história da computação voluntária começa junto com a publicação do primeiro sistema que abertamente utilizava recursos de computadores voluntários, o Great Internet Mersenne Prime Search (GIMPS) ${ }^{1}$ em 1996, que procurava por grandes números primos. O problema dos números primos é bastante leve (requer poucos recursos) em termos de tráfego, pois é enviado apenas um número e a resposta é afirmativa ou negativa, porém exige um processamento de média ou longa duração. A estratégia utilizada pelo GIMPS é bastante similar às utilizadas por Folding@home (LARSON et al., 2002) e ao SETI@home (ANDERSON et al., 2002) que são sistemas que conseguiram alcançar um grande poder computacional com a computação voluntária (ANDERSON, 2004). Os problemas com estas características (baixo tráfego de dados e processamento de média ou longa duração) se adequaram bem às características da computação voluntária.

A base fundamental da computação voluntária (BEBERG et al., 2009) é simples se comparada com suas questões em aberto, relacionadas à sua implantação e/ou aplicação (DETHIER et al., 2008; DUAN et al., 2012; DORNEMANN et al., 2012; DIAS et al., 2010). Antes de mais nada deve existir um projeto que aceite utilizar o processamento de outros computadores, chamados de voluntários (ou workers). Em geral esses computadores são pessoais e não identificados. O projeto deve estar bem dividido em partes menores, essas partes são chamadas de atividades (tasks, jobs ou work units), cada atividade contém uma função ou um programa, além dos dados de entrada necessários. O responsável então publica o projeto para que os voluntários o acessem (diz-se que o voluntários são "recrutados"). Os voluntários baixam uma atividade de cada vez e, em seguida, a processam e enviam os resultados de cada atividade de volta ao projeto.

A natureza da computação voluntária é extremamente volátil (DIAS et al., 2010). Os projetos, em sua maioria, estão alocados na internet, o que implica em problemas como instabilidade de conexões, velocidade de transmissão e atraso de envio. Esses problemas limitam a abrangência dos projetos, pois projetos com atividades muito longas ou com alto tráfego de dados podem ser pouco eficientes. Em geral os projetos possuem atividades formadas de arquivos pequenos que gastam no máximo algumas horas de processamento. Além disso, os sistemas também são bastante dinâmicos, um voluntário pode entrar e sair do sistema quando bem entender, seja durante uma transmissão ou um processamento. Por

1 http://www.mersenne.org 
não utilizar computadores identificados, alguns sistemas enviam a mesma atividade para vários voluntários, isso evita que algum comportamento malicioso distorça o resultado do projeto e evita os problemas relacionados a voluntários saindo do sistema durante a execução de atividades.

\subsection{Desktop Grids}

As estruturas e os processos de um desktop grid são bem parecidos com de um projeto de computação voluntária (SCIENCETALK, 2011). A principal diferença está na natureza volátil dos participantes na computação voluntária. Um desktop grid não trabalha com voluntários, mas o mesmo conceito de worker é utilizado. Os computadores participantes do grid são de conhecimento do responsável pelo projeto e estes são mantidos em um ambiente controlado. Um worker não sai do sistema sem o conhecimento do responsável do projeto e, por mais que ainda possam existir falhas, estas são mais raras.

\subsection{Composição de Serviços}

A composição de serviços tem o objetivo de combinar serviços para criar aplicações mais complexas. Pode-se dividir a composição de serviços em duas classes: orquestrada e coreografada.

O funcionamento da execução de serviços consiste de um programa interessado na execução de um serviço fazer uma requisição, enviando os parâmetros necessários, para que o serviço execute algum tipo de processamento e retorne uma saída. Esse comportamento é similar à computação voluntária, com diferença de que um serviço não pode executar um processamento diferente daquele que foi previamente definido, enquanto que na computação voluntária tipicamente são enviados a requisição e o código que deve ser processado.

Na orquestração de serviços a resposta do serviço é retornada a quem fez a requisição. Já no caso de coreografia, os serviços se comunicam entre si e as saídas podem ser direcionadas para servirem de entradas para outros serviços. Esse comportamento coreografado possibilitou melhorias significativas em termos de escalabilidade e transferência de dados (DUAN et al., 2012).

A aplicação de técnicas de computação P2P à computação voluntária parte de um princípio similar à coreografia de serviços, isto é, possibilitar a comunicação entre os 
diversos voluntários do sistema sem precisar passar por um coordenador (ou orquestrador) do projeto.

\subsection{Escalonamento com ponto-a-ponto}

Diversos trabalhos na literatura já chamam a computação voluntária de PQP Computing (entre outros nomes). Isso se deve ao fato de na computação voluntária haver a transferência de ações/responsabilidades de uma entidade (responsável pelo projeto) para outras (voluntários). Porém, de um modo geral, a arquitetura da maioria dos sistemas que usam computação voluntária segue o esquema cliente-servidor.

Os voluntários não se comunicam de forma descentralizada, isto é, para conseguir algum tipo de recurso (código ou dados) não é possível consegui-lo por meio de outro participante que não seja o servidor. Este mestrado atuou justamente nesta questão: permitir que os voluntários se comuniquem entre si com o intuito de diminuir a sobrecarga do servidor.

No Capítulo 3 são apresentados e discutidos outros trabalhos disponíveis na literatura nos quais os voluntários se comunicam entre si.

\subsection{Benchmark}

Durante a revisão na literatura não encontramos métodos amplamente utilizados para medir o desempenho computacional da execução de workflows científicos em ambientes distribuídos. Por isso foi utilizado um conjunto de workflows que são exemplos simplificados (toy examples), baseados em algumas estruturas básicas de workflows. Essas estruturas básicas foram definidas em (BHARATHI et al., 2008) e estão exibidas e nomeadas na figura 1. Os autores do referido artigo deixam claro que o número de atividades pode variar em cada uma destas estruturas. No decorrer deste trabalho as estruturas utilizadas para medir o desempenho seguem exatamente a mesma quantidade de atividades e estrutura utilizadas pelos autores e representadas na figura 1, variando apenas na quantidade de cópias das estruturas utilizadas nos testes (conforme será detalhado no capítulo 5). As atividades são representadas como retângulos e os dados são fornecidos pelas saídas das atividades ou indicados como já disponíveis pelos círculos azuis. 
Figura 1 - Estruturas básicas de workflows

(a) Pipeline

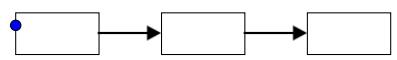

(b) Data Distribution

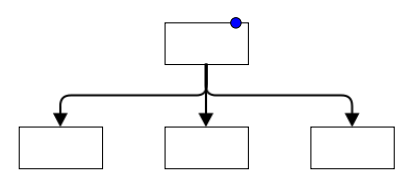

(d) Data Redistribution

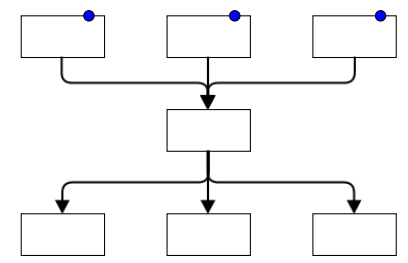

(c) Data Aggregation



Fonte: Caio Rafael do Nascimento Santiago, 2015

Essas estruturas básicas representam a forma como as atividades, chamadas de Jobs por Bharathi et al. (2008), se relacionam com os dados. Com base nestas 4 estruturas é possível construir workflows mais complexos por meio combinações e da variação do número de atividades, desde que este possam ser representados com dígrafos.

\subsection{Infraestrutura}

A história dessa infraestrutura que foi estendida neste mestrado se inicia nos anos 90. A primeira versão chamada WOODSS (A Spatial Decision Support System based on Workflows) (SEFFINO et al., 1999) foi implementada sobre um Sistema de Informação Geográfica para capturar e armazenar interações dos usuários, permitindo o compartilhamento, atualização e reexecução de experimentos).

WOODSS evoluiu para um sistema de gerenciamento de workflows genérico (MEDEIROS et al., 2005) visando a auxiliar cientistas na especificação, anotação e compartilhamento de seus modelos e experimentos. A evolução da infraestrutura incluiu o armazenamento dos workflows em bancos de dados (incluindo dados de entrada e resultados), a anotação semântica e descrição de serviços na forma de objetos digitais (fáceis de serem reusados e executados) e uma primeira solução para a composição automática de serviços.

Algumas das últimas extensões da infraestrutura incluem o armazenamento de proveniência de dados, o uso de ontologias para descrever dados e serviços, e para permitir a composição automática de serviços Web semânticos usando planejamento de inteligência 
artificial, o desenvolvimento de mecanismos de rastreabilidade, e o desenvolvimento de mecanismos para facilitar o reúso de componentes de software (DIGIAMPIETRI; PEREZALCAZAR; MEDEIROS, 2007a; BARGA; DIGIAMPIETRI, 2008; DIGIAMPIETRI et al., 2013; ZUNIGA et al., 2014).

Este mestrado utiliza e expande a infraestrutura criada no decorrer do doutorado do orientador no Instituto de Computação da UNICAMP e estendido dentro do projeto Jovem Pesquisador em Centros Emergentes - FAPESP do orientador, intitulado "Gerenciamento e Composição Automática de Serviços Web Semânticos". Os próximos parágrafos apresentam brevemente o projeto Jovem Pesquisador.

A arquitetura do projeto foi originalmente prototipada para a especificação e anotação de workflows científicos em bioinformática. Os workflows são armazenados em bancos de dados e as ontologias são utilizadas para aumentar a semântica na composição automática de workflows. Além disso, foram inseridas funcionalidades ligadas a rastreabilidade de experimentos usando um modelo de proveniência de dados e serviços para permitir o armazenamento eficiente da proveniência dos experimentos (BARGA; DIGIAMPIETRI, 2008; DIGIAMPIETRI; PEREZ-ALCAZAR; MEDEIROS, 2007b).

O projeto Jovem Pesquisador visou a estender a pesquisa realizada durante o doutorado do orientador, enfocando na combinação de diferentes técnicas de Inteligência Artificial (IA) para a composição de serviços; execução dos serviços compostos, estudo do melhor modelo ontológico a ser usado pela arquitetura para possibilitar o gerenciamento de informação semântica; uso de padrões de workflows; e desenvolvimento de técnicas para correção, em tempo de execução, de serviços defeituosos. Além disso, nesse projeto o conceito de atividade foi generalizado permitindo-se que não sejam utilizados apenas serviços web, mas também classes desenvolvidas na linguagem de programação Java e aplicativos locais. Esta generalização ampliou a disponibilidade das atividades para criação dos workflows permitindo que a infraestrutura proposta seja facilmente utilizada em diversos domínios (DIGIAMPIETRI et al., 2011; DIGIAMPIETRI et al., 2012; DIGIAMPIETRI et al., 2013; DIGIAMPIETRI et al., 2014b; ZUNIGA et al., 2014).

A figura 2 apresenta a arquitetura geral do projeto Jovem Pesquisador, que neste trabalho de mestrado foi expandida para aumentar a capacidade de modularização do "Motor do Workflow", tornando possível a utilização de diversos algoritmos de escalonamento e a comunicação com computadores voluntários. 
Figura 2 - Arquitetura do projeto Jovem Pesquisador



REPOSITÓRIOS

Fonte: Luciano Antonio Digiampietri, 2007

A arquitetura exibida na figura 2 está dividida em quatro níveis: Interface, Processamento, Gerenciador de Dados e Repositórios.

A Interface contém uma interface gráfica que apresenta aos usuários todas as funcionalidades da infraestrutura. A Camada de Processamento é composta por diversos módulos que são responsáveis por: registro e descoberta de Serviços Web, projeto de workflows (incluindo a composição (semi-)automática) e execução de workflows. O Gerenciador de Dados é uma interface (middleware) entre os repositórios de dados e o resto do sistema. Ele contém funcionalidades de interoperabilidade, integração de dados e rastreabilidade. A Camada dos Repositórios armazena informações sobre serviços, estruturas de dados, ontologias, dados de workflow e proveniência e regras de transformações entre dados. Os repositórios são compatíveis com os modelos ontológicos mais comumente utilizados (WSMO, WSDL-S e OWL-S). 


\subsection{Considerações Finais}

Este capítulo apresentou os conceitos fundamentais que foram utilizados para a elaboração deste trabalho. Pelo fato do enfoque deste trabalho ser no processamento de workflows científicos, os problemas que enfocam alto tráfego de dados e longo processamento. Também foram apresentados alguns conceitos da computação voluntária, das questões que envolvem a técnicas de computação ponto-a-ponto, além de como a inspiração em coreografia de serviços poderá ser empregada na melhora do desempenho de sistemas de computação voluntária.

O capítulo seguiu com a descrição das estruturas básicas de workflows que serviram de base na avaliação do desempenho dos métodos de escalonamento. Por fim, o capítulo foi encerrado com a apresentação da infraestrutura que serviu como base para a criação da infraestrutura utilizada para a construção dos métodos de escalonamento. 


\section{REVISÃO SISTEMÁTICA}

Este capítulo sumariza os principais aspectos da revisão sistemática realizada para identificar quais algoritmos de escalonamento podem ser utilizados para a computação voluntária a fim de tomar vantagem da computação ociosa. O texto completo da revisão sistemática está disponível na web ${ }^{1}$.

\subsection{Resumo da Revisão}

A revisão sistemática foi realizada em novembro de 2013 visando a identificar quais algoritmos de escalonamento podem ser utilizados para a computação voluntária, quais as estruturas de dados utilizadas e técnicas de avaliação/validação empregadas.

Três bibliotecas digitais foram consultadas: ACM Digital Library² ${ }^{2}$ IEEE Xplore ${ }^{3}$, ScienceDirect ${ }^{4}$ e a busca originalmente resultou em 97 artigos. Porém, após a aplicação dos critérios de inclusão e exclusão apenas sete artigos foram selecionados. Os detalhes sobre as strings de busca utilizadas e critérios podem ser encontrados no relatório técnico produzido $^{1}$.

As subseções a seguir apresentam as principais características dos artigos selecionados e a conclusão deste capítulo identifica alguns pontos da revisão que foram considerados no desenvolvimento deste mestrado.

\subsubsection{Estrutura de dados}

Para entender melhor como os computadores estão organizados e como trabalham em cada um dos artigos as seguintes questões foram levantadas:

- Q1 - Como os nós se relacionam entre si?

- Q2 - Quais os tipos de classes dos nós?

- Q2.1 - Qual o papel de cada classe?

- Q3 - As atividades dever ser independentes?

1 http://www.each.usp.br/digiampietri/relatorios/revisaosistematica_crns.pdf

http://dl.acm.org

http://ieeexplore.ieee.org

http://sciencedirect.com 
- Q4 - Existe algum meio que centralize parcialmente o escalonamento?

- Q5 - Existe algum tipo de cache de dados nos nós? E se sim, como é feito?

- Q6 - Existe algum tipo de checkpoint sobre os estados do processamento corrente?

- Q6.1 - Como é feito o checkpoint?

Na tabela 1 estão as repostas a estas questões, extraídas dos artigos analisados.

Tabela 1 - Dados extraídos dos artigos referentes à estrutura de dados

\begin{tabular}{|c|c|c|c|c|c|c|c|c|}
\hline ARTIGO & Q1 & Q2 & Q2.1 & Q3 & Q4 & Q5 & Q6 & Q6.1 \\
\hline $\begin{array}{l}\text { (CELAYA; } \\
\text { ARRONATE- } \\
\text { GUI, } \\
2010)\end{array}$ & $\begin{array}{l}\text { VBI- } \\
\text { Tree } \\
\text { (JAGA- } \\
\text { DISH, } \\
\text { 2006) }\end{array}$ & $\begin{array}{l}\text { Routing } \\
\text { node } \\
\text { Execution } \\
\text { node } \\
\text { Submission } \\
\text { node }\end{array}$ & $\begin{array}{l}\text { Possui informações sobre a } \\
\text { disponibilidade de recurso } \\
\text { do Execution nodes } \\
\text { Executa os jobs } \\
\text { Criador das atividades e } \\
\text { pelo escalonamento inicial }\end{array}$ & Não & Não & NA & Não & NA \\
\hline $\begin{array}{l}\text { (KWAN; } \\
\text { JOGESH, } \\
2010)\end{array}$ & Super-peer & $\begin{array}{l}\text { Super-peer } \\
\text { Worker } \\
\text { Client }\end{array}$ & $\begin{array}{l}\text { Escalonam atividades para } \\
\text { os worker } \\
\text { Processam atividades } \\
\text { Criador das atividades e } \\
\text { pelo escalonamento inicial }\end{array}$ & Sim & Sim & Não & NA & NA \\
\hline $\begin{array}{l}\text { Murata } \\
\text { 2008(MU- } \\
\text { RATA et al., } \\
2008)\end{array}$ & Vizinhança & $\begin{array}{l}\text { BOINC } \\
\text { Workers }\end{array}$ & $\begin{array}{l}\text { É a fonte inicial das ativi- } \\
\text { dades } \\
\text { Processam atividades e po- } \\
\text { dem reescalonar atividade } \\
\text { para outros workers }\end{array}$ & Sim & Sim & NA & Não & NA \\
\hline $\begin{array}{l}\text { (Wen Dou et al., } \\
\text { 2003) }\end{array}$ & Vizinhança & $\begin{array}{l}\text { Não possui } \\
\text { classes }\end{array}$ & NA & Sim & Não & NA & Não & NA \\
\hline $\begin{array}{l}\text { (ZHAO; YANG; } \\
\text { XU, 2009) }\end{array}$ & Vizinhança & $\begin{array}{l}\text { Não possui } \\
\text { classes }\end{array}$ & NA & Não & Não & NA & Não & NA \\
\hline $\begin{array}{l}\text { (RIUS et al., } \\
2012 \text { ) }\end{array}$ & Super-peer & $\begin{array}{l}\text { Master } \\
\text { Manager } \\
\text { Worker }\end{array}$ & $\begin{array}{l}\text { Criador das atividades e } \\
\text { pelo escalonamento inicial } \\
\text { Escalonam atividades para } \\
\text { os workers } \\
\text { Processam atividades }\end{array}$ & Sim & Sim & Não & NA & NA \\
\hline $\begin{array}{l}\text { (MASTROIANNI } \\
\text { et al., 2009) }\end{array}$ & Super-peer & $\begin{array}{l}\text { Job mana- } \\
\text { ger } \\
\text { Worker }\end{array}$ & $\begin{array}{l}\text { Age como backbone dos } \\
\text { Super-peers, e junta o wor- } \\
\text { kers aos jobs } \\
\text { Disponibiliza os jobs e os } \\
\text { dados para os Workers } \\
\text { Recebe os dados de fontes } \\
\text { externas e transmite para } \\
\text { os Data cachers e para o } \\
\text { Workers } \\
\text { Disponibiliza os job para os } \\
\text { Super-peers e Data cachers } \\
\text { Processam atividades }\end{array}$ & Sim & Sim & Sim & $\begin{array}{l}\text { Cache } \\
\text { sobre jobs } \\
\text { e dados, } \\
\text { estes são } \\
\text { armazena- } \\
\text { dos no } \\
\text { Data } \\
\text { cachers } \\
\text { para serem } \\
\text { executados } \\
\text { múltiplas } \\
\text { vezes }\end{array}$ & NA \\
\hline
\end{tabular}

Fonte: Caio Rafael do Nascimento Santiago, 2015

Pode-se notar que existe um equilíbrio entre os artigos que utilizam estratégias baseadas em vizinhança e super-peer. A vizinhança nestes casos resulta em uma modelagem de grafos enquanto que os super-peers se aproximam mais de uma modelagem baseada em árvores, assim como a estratégia baseada na VBI-Tree. Uma exceção a isso é o caso (RIUS 
et al., 2012) em que existem tantos elementos envolvidos no sistema que a modelagem se aproxima tanto de árvores quanto de grafos. Devido à modelagem utilizada nestes artigos, os computadores são tipicamente chamados de nós ou peers. A forma como os computadores se relacionam nas propostas está intimamente ligada à existência de algum meio que centralize parcialmente o escalonamento, pois os artigos baseados em super-peers estão de alguma forma centralizando o escalonamento, além destes, no trabalho de Murata et al. (2008) é apresentada uma proposta dependente do BOINC (ANDERSON, 2004) pois todas as atividades partem inicialmente do BOINC.

Quanto às classes, apenas dois artigos não as utilizam, (Wen Dou et al., 2003) e (ZHAO; YANG; XU, 2009). Nestes trabalhos os computadores também se relacionam por meio de vizinhanças, as estratégias de escalonamento são mais simples e baseadas em decisões locais. Entre os vários nomes que cada um dos artigos escolheu, um tornouse recorrente, são chamados de worker os computadores responsáveis por processar as atividades (também chamadas de Jobs pela maioria dos artigos). Algumas destas classes não são computadores voluntários (em geral as classes que não são workers), mas isso pode ser um fator complicador, pois exigem computadores dedicados e que apresentam um fator maior de confiança. Quanto maior o número de classes maior é o esforço inicial do responsável pelo sistema, por exemplo, a solução proposta por Mastroianni et al. (2009) tem uma configuração inicial com quatro computadores.

A maioria dos artigos trabalha apenas com atividades independentes, i.e., não possuem uma estratégia diferente para atividades dependentes. No trabalho de Zhao, Yang e Xu (2009) uma limitação é que as atividades devem ser todas dependentes, este algoritmo trabalha apenas com problemas divisíveis (problemas de divisão e conquista). No trabalho de Celaya e Arronategui (2010) as atividades podem ser independentes mas isso pode não ser tão eficiente uma vez que o algoritmo de escalonamento está melhor preparado para trabalhar com atividades dependentes. A maioria dos artigos trabalha com atividades do tipo Bag-of-Task, i.e., um conjunto de atividades que não se comunicam e são independentes.

O cache de dados e o checkpoint do processamento são questões importantes, pois algumas atividades podem ter um custo muito grande tanto de transferência de dados quanto de processamento. Nenhum artigo tratou de questões de checkpoints como forma de minimizar os danos da ocorrência de falhas, i.e., quando um computador faz backups periódicos do estado das variáveis da atividade que esteja processando. Também não têm 
formas preventivas de lidar com falhas como, por exemplo, no trabalho de Zhou e Lo (2006). Apenas um artigo aplica cache (RIUS et al., 2012), o cache fica nos Data cachers que funcionam com Job managers e Data sources, mas aparentemente o sistema não está preparado para aceitar computadores voluntários para essa tarefa, portanto em nenhum dos sistemas os voluntários funcionam como cachers do sistema.

\subsubsection{Algoritmo de escalonamento}

Os algoritmos de escalonamento não puderam ser descritos em perguntas simples e, portanto, serão descritos de forma extensa.

Os algoritmos propostos por Wen Dou et al. (2003) e Zhao, Yang e Xu (2009) são relativamente parecidos e serão descritos juntos. Nestes casos não existem classes e os computadores tanto processam quanto escalonam atividades para seus vizinhos. No trabalho de Wen Dou et al. (2003) as atividades já estão todas distribuídas no sistema e um computador, quando sobrecarregado, escalona uma atividade para o vizinho menos sobrecarregado. Já no trabalho Zhao, Yang e Xu (2009) o computador recebe uma atividade e a divide, em seguida transmite os filhos da atividade para seus vizinhos. Este algoritmo trabalha com uma classe muito limitada de algoritmos e não fica claro se esta solução é eficiente em todos os casos, por exemplo, se considerarmos o merge sort no qual as etapas de divisão, conquista e combinação são rápidas e a transferência de dados pode ser custosa esse algoritmo não dá garantias de eficiência. Ambos os algoritmos são simples e executam transferências baseadas em decisões locais e, por isso, também podem acarretar em problemas de mínimos locais.

Os algoritmos apresentados por Kwan e Jogesh (2010) e Rius et al. (2012) também possuem algumas características em comum. Ambos possuem três tipos de classes: uma que é a fonte das atividades, uma que processa as atividades e super-peers que agem entre a primeira e a segunda classe. O escalonamento é feito em duas partes, na primeira, a fonte das atividades escalona a atividade para o super-peer, em seguida o super-peer escalona a atividade para o computador que a processará. No algoritmo de Kwan e Jogesh (2010), a primeira etapa é probabilística, onde o super-peer com menor sobrecarga tem maior probabilidade de receber uma atividade. Os super-peers se comunicam entre si trocando informação sobre as suas próprias cargas, a segunda o super-peer escolhe o melhor computador dentro de um deadline. Já na primeira etapa do algoritmo de Rius et al. 
(2012) é utiliza uma fórmula que combina a reputação, o centro de massa e a capacidade computacional do vizinhos para escolher o super-peer, e na segunda etapa o super-peer escalona a atividade para o computador com o menor custo.

O algoritmo de escalonamento apresentado por Murata et al. (2008) é uma extensão do BOINC (ANDERSON, 2004), que já é amplamente conhecido e utilizado. A diferença é que os computadores que processam as atividades se organizam em subgrupos e dentro de cada subgrupo todos se comunicam entre si. O BOINC continua fornecendo as atividades, mas quando um computador está sobrecarregado ele re-escalona uma atividade para um membro de seu subgrupo que esteja mais livre. Isso diminui a taxa de transferência do BOINC e consequentemente aumenta a escalabilidade do sistema.

A estratégia adotada por Mastroianni et al. (2009) é relativamente simples. Os computadores que processam as atividades (workers) as pedem para os Super-peers e estes repassam o pedido para os Data cachers que completam o envio. Os Data cachers por sua vez recebem as atividades do Job managers. Os workers também devem pedir os dados, o processo é o mesmo, mas em vez dos Data cachers receberem os dados do Job manager eles enviam o pedido para o Data source que o repassa para o worker. As respostas dos workers são enviadas para o Job manager.

Por fim, a abordagem proposta por Celaya e Arronategui (2010) utiliza uma estratégia de árvore que possui três classes: a raiz é a fonte das atividades (submission node), os galhos são os routing nodes, os galhos e as folhas processam as atividades (execution nodes). O problema é descrito como um DAG (Directed acyclic graph), o submission node separa o caminho mais longo e o envia para os primeiros routing nodes. Cada routing node possui uma sumarização dos dados de disponibilidade nos execution nodes que estão abaixo dele, com base nesta informação ele escalona a lista de atividades dentro das janelas de disponibilidade, a qual ele conhece de forma gulosa (similar ao problema da agenda), isto é, repassando as atividades para baixo na topologia de árvore. Os routing nodes fazem isso repetidamente até que as atividades cheguem às folhas.

\subsubsection{Avaliação do escalonamento}

Assim como na análise feita sobre a estrutura de dados, para analisar a avaliação do escalonamento perguntas foram preparadas, são elas: 
- Q1 - O método de avaliação do escalonamento foi uma simulação?

- Q2 - Qual é a configuração e quantos computadores foram envolvidos nos testes?

- Q3 - Qual a conexão entre os computadores?

- Q4 - A avaliação tratou simulação de falhas?

- Q5 - Qual foi o problema abordado na avaliação?

- Q6 - Quais métricas foram utilizadas para medir o desempenho do escalonamento?

Na tabela 2 estão respostas a estas questões extraídas dos artigos analisados.

Tabela 2 - Dados extraídos dos artigos referentes à avaliação do escalonamento

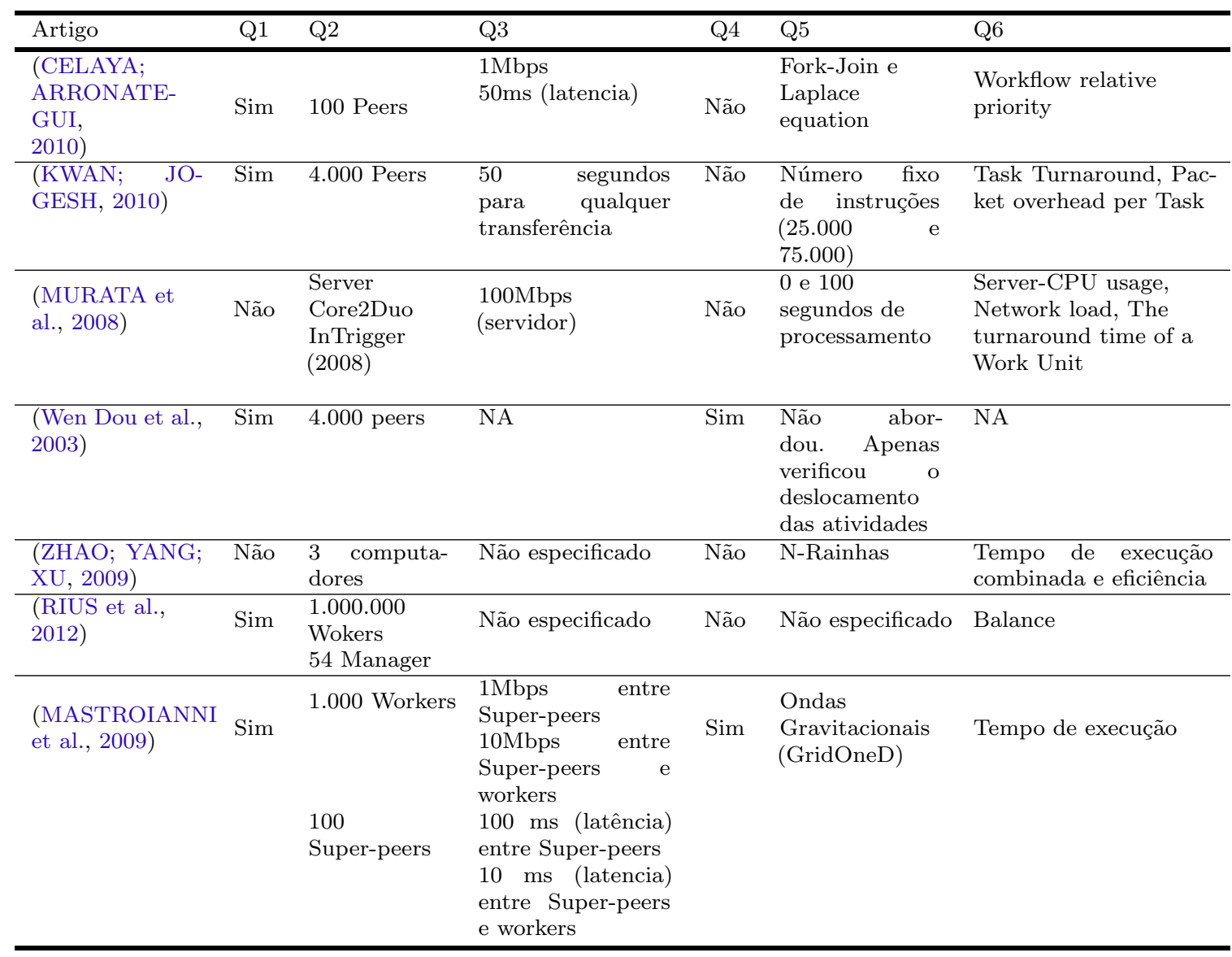

Fonte: Caio Rafael do Nascimento Santiago, 2015

Pode-se notar que a maioria dos testes foram simulações e isso é plausível considerandose o montante de computadores em alguns testes seria necessária uma quantidade muito grande de recursos para envolver 10.000.000 de computadores reais (CELAYA; ARRONATEGUI, 2010).

Apenas dois artigos não fizeram simulações. No trabalho de Murata et al. (2008) foram utilizados um computador comum como fonte das atividades (um computador Intel 
Core2Duo), já os outros participantes são os computadores que compunham o InTrigger ${ }^{5}$ em 2008. O InTrigger é um grid formado por computadores pessoais localizado no japão, o grid está em constante evolução, mas na época deste experimento possuía 222 computadores, mas as configurações de rede não foram especificadas nas condições da época. O outro trabalho (ZHAO; YANG; XU, 2009) a não realizar uma simulação utilizou três computadores não especificados e também não especificou as configurações de rede utilizadas.

Os artigos que fizeram simulações são abrangentes nos elementos envolvidos em seus experimentos. O trabalho de Rius et al. (2012) foi o que mais utilizou computadores na avaliação do escalonamento (1.000.000 como workers e mais 54 computadores como managers). As configurações de rede não foram informadas.

Três trabalhos utilizam centenas ou milhares de computadores (KWAN; JOGESH, 2010; Wen Dou et al., 2003; MASTROIANNI et al., 2009), sendo que no trabalho de Mastroianni et al. (2009) também foram simulados 100 super-peers. Já as configurações de rede são bem distintas. Kwan e Jogesh (2010) fixaram todas as transferências em um tempo fixo de 50ms. Wen Dou et al. (2003) não informaram, e Mastroianni et al. (2009) utilizam configurações separadas entre os super-peers e dos super-peers para o workers, respectivamente são: $1 \mathrm{Mbps}$ com latência de 100ms e 10Mbps com latência de $10 \mathrm{~ms}$.

Por fim, o artigo que simulou a menor quantidade de computadores foi o de Celaya e Arronategui (2010), no qual foram simulados 100 computadores conectados em por uma banda de $1 \mathrm{Mbps}$ com latência de $50 \mathrm{~ms}$.

Quanto a simulação de falhas, apenas dois trabalhos (MASTROIANNI et al., 2009; Wen Dou et al., 2003) realmente fazem simulações de falha, nos outros até são apresentados mecanismos de tratamento de falhas, mas os autores não fizeram experimentos demonstrando sua eficiência.

Os problemas abordados durante a avaliação dos escalonadores foram dos mais variados. Wen Dou et al. (2003) não utilizaram um problema específico, seu objetivo era prova que o caminho mais curto de um computador a outro era de no máximo sete intermediários, isso em si não é uma forma de se comprovar a eficiência do algoritmo. Kwan e Jogesh (2010) utilizaram várias atividades de tamanho fixo de 25.000 e 75.000 instruções e avaliou com o Task Turnaround e o Packet Overhead per Task, por utilizar o deadline na composição do algoritmo o problema abordado é muito propício, pois poucos problemas reais podem ter seu deadline facilmente calculado. Murata et al. (2008) utilizaram uma 
abordagem similar, mas fixando o tempo de processamento de cada atividade a uma constante, e avaliou com o Server-CPU usage e o turnaround time of a Work Unit. Rius et al. (2012) não especificou um problema e avaliou com Scheduling Overhead e o Load Balance. Os artigos (MASTROIANNI et al., 2009), (CELAYA; ARRONATEGUI, 2010) e (ZHAO; YANG; XU, 2009) são mais realísticos. Mastroianni et al. (2009) utilizaram Ondas Gravitacionais (GridOneD) avaliando o tempo de execução. Celaya e Arronategui (2010) utilizaram Fork-Join e Laplace equations e avalia com workflow relative priority. Zhao, Yang e Xu (2009) utilizaram o problema das N-Rainhas com o tempo de execução combinado dos três computadores e a eficiência.

\subsection{Comparação com a Solução Desenvolvida no Mestrado}

A revisão da literatura inspirou a solução proposta e desenvolvida neste mestrado tanto fornecendo algumas bases para a construção da solução como apresentando alguns problemas em aberto que, neste projeto, tentamos solucionar. Os próximos parágrafos apresentam um breve paralelo entre os trabalhos correlatos e a solução proposta. No próximo capítulo (Capítulo 4) será detalha a solução proposta.

A solução proposta e desenvolvida nesta dissertação utilizou algumas estratégias diferentes daquelas observadas na revisão. A principal diferença foi a construção de uma estratégia diferenciada para o compartilhamento/reutilização de parâmetros por meio da utilização de conceitos de computação P2P entre os computadores voluntários. Em situações em que os parâmetros são reutilizados a solução visa a diminuir a banda de upload do servidor e uma redução no tempo total do sistema. Isso ocorre porque a solução considera os parâmetros como estruturas independentes das atividades que os utilizam e ao fato dos voluntários guardarem e compartilharem os parâmetros de forma proativa enquanto estão processando outras atividades.

Celaya e Arronategui (2010) apresentaram uma estratégia voltada para o tratamento de atividades dependentes, mas a solução desenvolvida neste mestrado não diferencia atividades dependentes ou independentes, e, portanto, não se prejudica por trabalhar com um determinado tipo ou outro de atividades. Mesmo que a reutilização de parâmetros se mostre eficiente para a execução de atividades dependentes (pois a saída produzida é inevitavelmente reutilizada) a solução proposta neste mestrado não está limitada a elas. 
Assim como nos trabalhos de Wen Dou et al. (2003) e Zhao, Yang e Xu (2009) a solução utiliza uma organização baseada em vizinhança e trabalha com decisões locais. Porém, diferentemente do trabalho de Zhao, Yang e Xu (2009) os dados transmitidos não se limitam aos últimos dados obtidos (além do sistema conseguir trabalhar livremente com atividades independentes). No trabalho de Wen Dou et al. (2003) as atividades são espalhadas pelos voluntários logo no início da execução (não sendo possível a execução de atividades dependentes) e são repassadas ao vizinhos conforme vão sendo processadas, mas não está claro se essas decisões de repasse são realizadas no momento em que o voluntário está processando a atividade.

Provavelmente o trabalho de Murata et al. (2008) seja o mais próximo da solução desenvolvida. Os voluntários baixam os dados do servidor e escalonam as atividades conforme a necessidade para seus vizinhos, contudo as atividades estão associadas aos parâmetros (nesse trabalho não é possível obter separadamente a atividade e os parâmetros). Não existe uma estratégia diferenciada para trabalhar com reutilização de parâmetros e nem para trabalhar com atividades dependentes.

\subsection{Considerações Finais}

Os artigos estudados apresentaram pouca diversidade de estrutura de dados, coisa que não acontece nos métodos de escalonamento e nos métodos de avaliação do desempenho dos escalonadores. Os métodos de escalonamento possuem desde soluções simples até as mais elaboradas e inteligentes, mas é difícil falar sobre a qualidade dos resultados destas soluções por causa da diversidade de métodos de avaliação. Por causa dos métodos de avaliação não foi possível comparar os resultados dos artigos vistos entre si e entre métodos que não utilizam técnicas de P2P. Os métodos de avaliação não seguiram nenhum padrão ou benchmark, o que poderia ser de grande ajuda para permitir uma comparação mais fidedigna entre as soluções.

Pôde-se perceber que existem poucos artigos sobre esse tópico, mostrando que é ainda um tópico incipiente e, portanto, um campo aberto para pesquisas. Talvez um motivo para explicar isso é que faz poucos anos que a internet chegou com velocidade relevante para usuários comuns a ponto de que estes pudessem baixar e transmitir dados desse tipo de sistema. 


\section{SOLUÇÃO DESENVOLVIDA}

Neste capítulo é apresentada a solução desenvolvida, cujo cerne corresponde a um método de escalonamento para computação voluntária que utiliza técnicas de computação P2P.

Adicionalmente, são detalhadas as modificações realizadas sobre a infraestrutura desenvolvida no projeto Jovem Pesquisador em Centros Emergentes - FAPESP do orientador. A maioria das extensões realizadas teve por objetivo tornar a infraestrutura mais modular e flexível, capaz de lidar com dados distribuídos.

Neste capítulo também é explicada a forma com a qual os computadores voluntários se comunicam. E, por fim, o algoritmo de escalonamento desenvolvido é apresentado e explicado passo a passo. Para a explicação deste algoritmo, inicialmente são apresentadas as classes envolvidas no processo e, em seguida, a sequência de atividades e/ou trocas de mensagens que ocorrem entre voluntários ou entre um voluntário e o servidor de forma a se executar um workflow.

Os códigos fonte desenvolvidos neste mestrado, bem como dados de teste, encontramse disponíveis na web ${ }^{1}$.

\subsection{Extensão do Modelo de Representação de Workflows}

Conforme apresentado na seção 2.7, este projeto estendeu um SGW existente. Na estrutura básica de representação do workflow desse SGW (Figura 3) era necessário que houvesse uma instância da classe Workflow se comunicando com uma instância da FilaDeExecucao para que esta então inicie o processamento. A classe Workflow detinha todo o conhecimento sobre as atividades (que são do tipo Executavel) e sobre o fluxo de dados entre cada uma delas. Apesar de esta estrutura ser bastante conveniente para a execução orquestrada de workflows simples, há algumas características que a tornam ineficiente na execução de workflows mais complexos e execução distribuída das atividades. Por exemplo, ela impossibilitava a criação de estruturas de controle de fluxo com laços ou condicionais de forma eficiente, além de impossibilitar que partes de um workflow executem sem o conhecimento completo do workflow.

1 http://www.each.usp.br/digiampietri/codigos/codigos_crns.7z 
Para lidar com as necessidade deste trabalho foram realizadas algumas modificações na estrutura básica de representação do workflow, como pode ser observado na figura 4. A classe Executavel recebeu as informações sobre o controle de fluxo que estavam armazenar em Workflow e cada atividade recebeu as informações referentes a si própria. As atividades agora sabem quais outras atividades precisam ser concluídas antes de começarem a executar (Depende de) e quais atividades devem ser avisadas quando forem concluídas (Responsável por). Anteriormente, apenas a classe Tarefa, que é um tipo particular de Executavel, possuía informações de entradas e saídas, mas atualmente todo Executavel possui essas informações, isso facilita a criação de outras classes que herdem Executavel. Com esta estrutura foi mais fácil criar outras classes para controle de fluxo (Loop, If e Or). O Loop, por exemplo, necessita criar novas instâncias de Executaveis em tempo de execução, o que não seria possível na estrutura anterior.

Figura 3 - Diagrama de classes da estrutura de representação do workflow

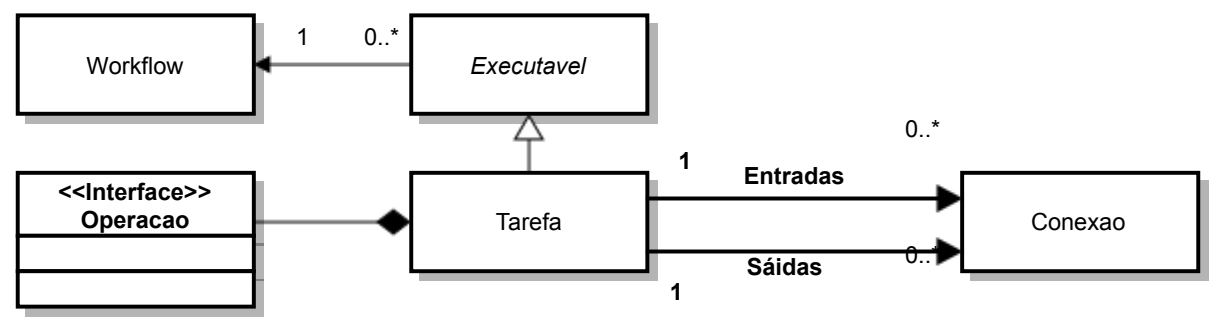

Fonte: Caio Rafael do Nascimento Santiago, 2015

Figura 4 - Diagrama de classes da estrutura modificada de representação do workflow

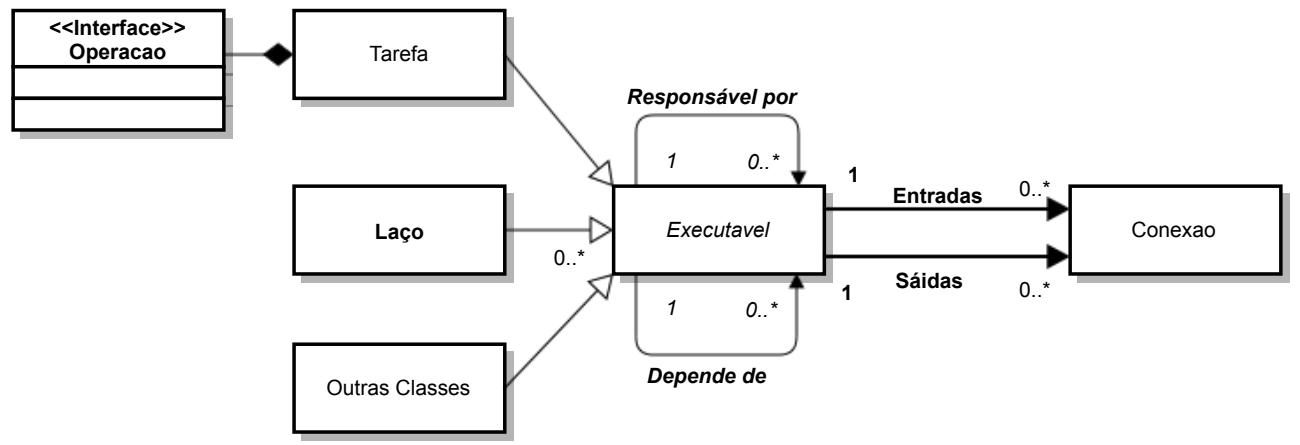

Fonte: Caio Rafael do Nascimento Santiago, 2015

A exclusão da classe Workflow também causou impactos no executor de workflows, como pode ser observado pelas diferenças entre as figuras 5 e 6 . A classe FilaDeExecucao 
não precisa mais das informações contidas em Workflow, basta saber quais atividades devem ser executadas logo no início do processo. Esta classe se responsabiliza apenas por executar os Executáveis marcados como prontos e marcar como prontos os próximos Executáveis que são ativados quando algum acaba, deixando assim a execução mais descentralizada e dinâmica.

A simplificação de todas estas estruturas e do algoritmo de escalonamento das atividades permitiu a abstração da classe FilaDeExecucao, facilitando assim o desenvolvimento de novos algoritmos de escalonamento e a escolha dentre os que estão disponíveis. Os processos de lidar com as atividades concluídas e habilitar as próximas atividades que podem ser executadas ficaram a cargo da classe abstrata, já o processo de escolha e execução das atividades ficou a cargo das classes filhas.

Foram implementados três algoritmos de escalonamento diferentes: um que utiliza apenas a execução local, tendo como estratégia o caminho mais longo; um baseado em sistemas de computação voluntária; e, por fim, o algoritmo que utiliza computação voluntária combinada com técnicas de computação P2P.

Figura 5 - Diagrama de classes da estrutura do executor Workflow

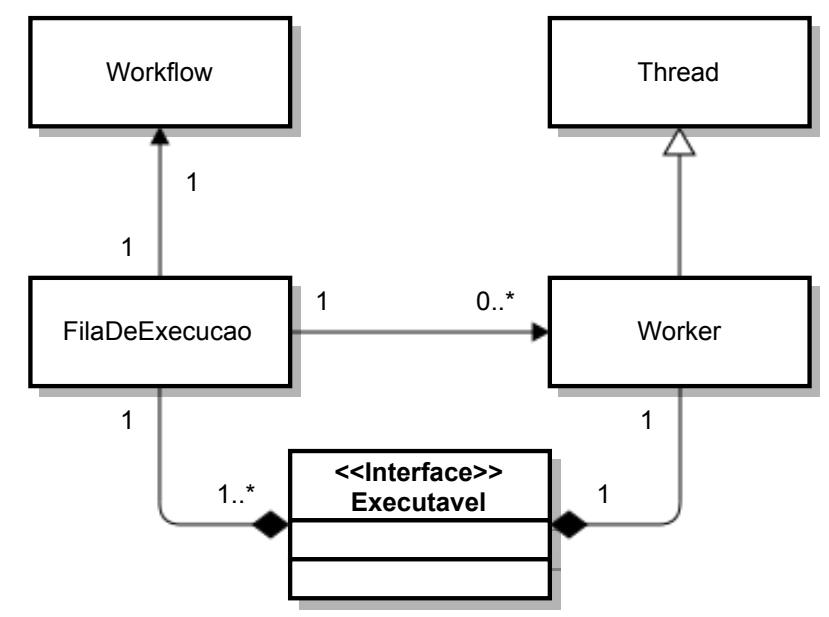

Fonte: Caio Rafael do Nascimento Santiago, 2015 
Figura 6 - Diagrama de classes da estrutura modificada do executor Workflow



Fonte: Caio Rafael do Nascimento Santiago, 2015

\subsection{Comunicação entre Computadores}

O algoritmo de escalonamento que combina computação voluntária com P2P exige que os computadores voluntários sejam capazes de se comunicar com outros voluntários. Para esta comunicação, foi desenvolvida a estrutura definida pelo diagrama da figura 7 .

Figura 7 - Diagrama de classes da estrutura de comunicação entre o servidor e os voluntários

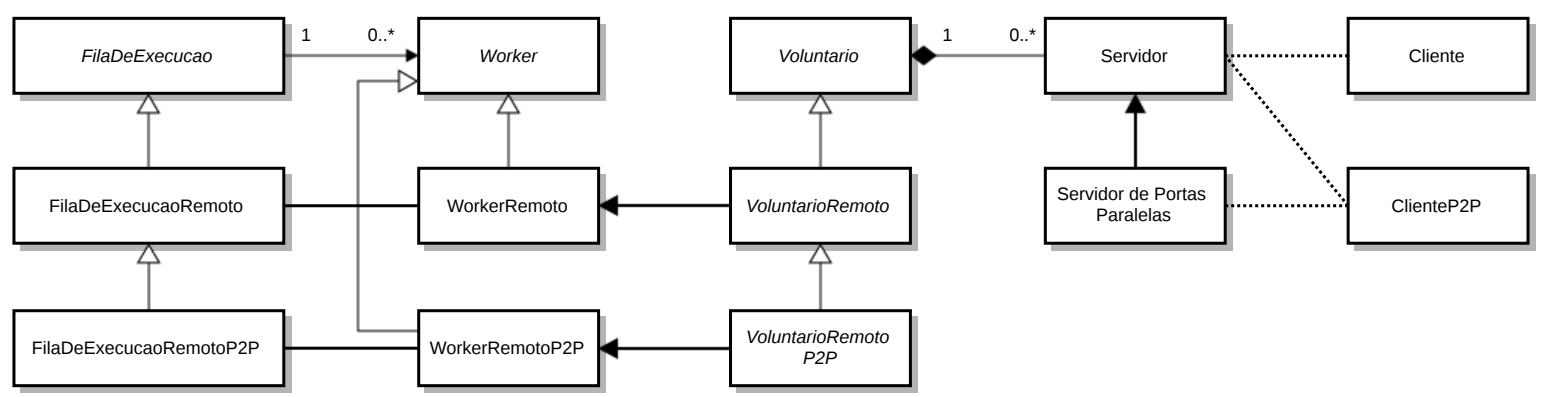

Fonte: Caio Rafael do Nascimento Santiago, 2015

Foram criadas duas aplicações separadas para desempenhar o papel dos clientes no sistema. A classe Cliente desempenha o papel do cliente na computação voluntária tradicional, enquanto que a classe ClienteP2P desempenha este papel na computação voluntária aplicando as técnicas de computação P2P. Ambas as classes se comunicam com a classe Servidor, que é a responsável por "recrutar" os voluntários e disponibilizá-los para a FilaDeExecucao (onde todo o processo de escalonamento acontece). 
A execução das atividades depende de que os voluntários recebam no mínimo três elementos que precisam ser serializados para serem transmitidos. O primeiro elemento é a atividade em si, como a estrutura toda é baseada em Java, a atividades é, em geral, uma função contida em uma classe. O segundo elemento são as classes associadas à classe principal da atividade, pois muitas vezes a execução de uma classe faz referências a outras classes e, portanto, estas classes precisam estar carregadas na memória antes de serem chamadas. Por último, os voluntários precisam receber as entradas das atividades. As classes foram serializadas em um processo de duas etapas: na primeira a definição da classe é adquirida em tempo de execução utilizando técnicas de reflexão; e na segunda, as instâncias dos objetos foram serializados utilizando o XStream ${ }^{2}$, uma biblioteca especializada para a serialização de objetos em Java. Quanto à serialização das entradas, foi necessária a criação de uma interface a ser utilizada pelo projetista do workflow para indicar o método de serialização dos dados, por causa da diversa gama de estruturas possíveis.

Os dois tipos de clientes se comunicam com o servidor por meio de mensagens, mas a diferença entre os dois é basicamente comportamental. A classe Cliente é passiva, pois possui um conhecimento restrito a uma atividade por vez e se comunica com o servidor apenas respondendo as mensagens. Já a classe ClienteP2P é ativa, o servidor que assume o papel de responder as mensagens do cliente e, além disso, também possui um conhecimento mais amplo do workflow e se comunica com outros voluntários para enviar e receber as entradas das atividades.

A classe Cliente baixa as entradas do servidor de forma continua. Já a classe ClienteP2P quebra as entradas em "pedaços" de tamanhos iguais, assim cada pedaço de uma entrada pode ser enviado por voluntários diferentes.

Para realizar a comunicação entre os voluntários foi criado um servidor auxiliar (o Servidor de portas paralelas), esse mecanismo ajuda os voluntários a abrirem portas, isto é, o voluntário envia um pacote de datagrama e o servidor informa os dados referentes à porta aberta pelo socket que enviou o datagrama. Ciente das portas abertas o voluntário já está apto a se comunicar com os outros utilizando estas portas. Por intermédio do servidor os clientes sinalizam o interesse em uma conexão para em seguida receberem os dados referentes a outro voluntário com uma porta aberta. Com esses dados, o voluntário inicia uma conexão utilizando o TseudoTCP. O Jitsi $i^{3}$ é uma aplicação de comunicação por

2 http://xstream.codehaus.org/

3 http://jitsi.org/ 
áudio e vídeo feita em Java, e sua comunidade mantém um framework chamado Ice $4 j^{4}$ que entre outras coisas contém o TseudoTCP. O TseudoTCP trabalha sobre o protocolo UDP e age na camada de aplicação para simular o protocolo TCP, essa estratégia permite estabelecer uma conexão utilizando apenas sockets UDP e, portanto, é possível estabelecer uma conexão sem a existência de uma porta fixa.

\subsection{Computação Voluntária aplicando técnicas de Ponto-a-Ponto}

O Algoritmo 1 foi desenvolvido no decorrer deste trabalho para lidar com algumas dos problemas da computação voluntária, como por exemplo, alta taxa de transferências de dados ou a latência do processamento de atividades.

O Algoritmo 1 mostra, em alto nível, o funcionamento da classe ClienteP2P, que é a responsável pela execução das atividades nos computadores voluntários aplicando P2P. A primeira diferença significativa é que o voluntário possui informações mais gerais sobre o workflow. Os objetos esquemáticos são uma simplificação das atividades, eles possuem apenas as identificações e as relações das atividades e servem para nortear o escalonamento das atividades. O cliente inicia o algoritmo requisitando uma lista de objetos esquemáticos, pois é a partir dessa lista que serão tomadas as decisões de escalonamento. Após se escolher a atividade (na Função Escolher melhor atividade) o cliente baixa os parâmetros e demais dados faltantes, inicia uma função em Segundo Plano e começa o processamento da atividade. Quando a atividade termina é enviado ao servidor os dados resultantes, e esses dados são marcados como não confirmados. Esta marcação ocorre porque, em uma situação em que o servidor exige redundância sobre os resultados das atividades, todas as atividades precisam terminar para o servidor saber se os resultados são válidos e, portanto, possam ser reutilizados pelo voluntário que o gerou.

Os objetos esquemáticos são postos em uma fila de prioridade onde são organizados conforme uma lista de características, são elas:

- As atividades são posicionadas depois das atividades das quais dependem;

- As atividades que têm mais parâmetros não disponíveis vêm depois;

- As atividades que têm mais parâmetros disponíveis vêm antes;

- As atividades com menos itens faltando para serem baixados vêm antes;

4 https://code.google.com/p/ice4j/ 


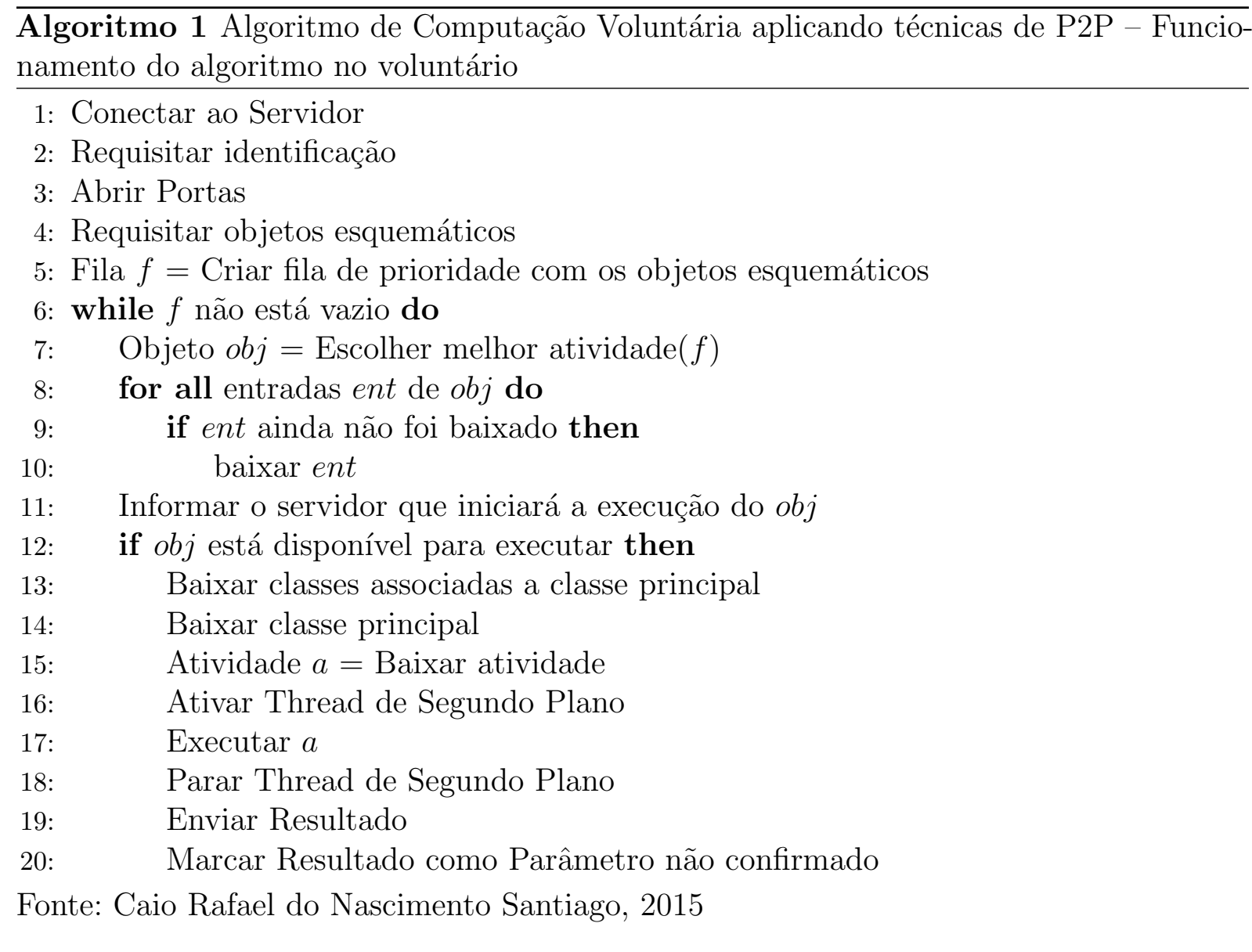

- As atividades com menos itens faltando para serem baixados ou baixando vêm antes;

- As atividades que têm mais parâmetros não confiáveis baixados vêm antes;

A partir desta relação de ordem entre as atividades o algoritmo sempre procura a melhor atividade para executar (Função Escolher melhor atividade presente no Algoritmo 2). Enquanto não existir nenhuma atividade disponível o algoritmo continua procurando parâmetros (entradas) para baixar. Se uma atividade se torna disponível para ser processada, o voluntário já está potencialmente mais preparado (por ter baixado os parâmetros com antecedência), uma estratégia mais proativa. Os voluntários procuram baixar os parâmetros, sempre que possível, dos seus vizinhos (caso eles os possuam). Se os parâmetros fossem baixados apenas nas vésperas de se executar uma atividade isso poderia significar numa perda de desempenho considerável, uma vez que a comunicação é potencialmente mais lenta, pois funciona de forma fragmentada, os objetos são baixados em pequenas partes por vez e existe uma maior concorrência pelos parâmetros.

Esta função também verifica se os parâmetros marcados como não confiáveis foram validados pelo servidor e se os downloads foram concluídos. 


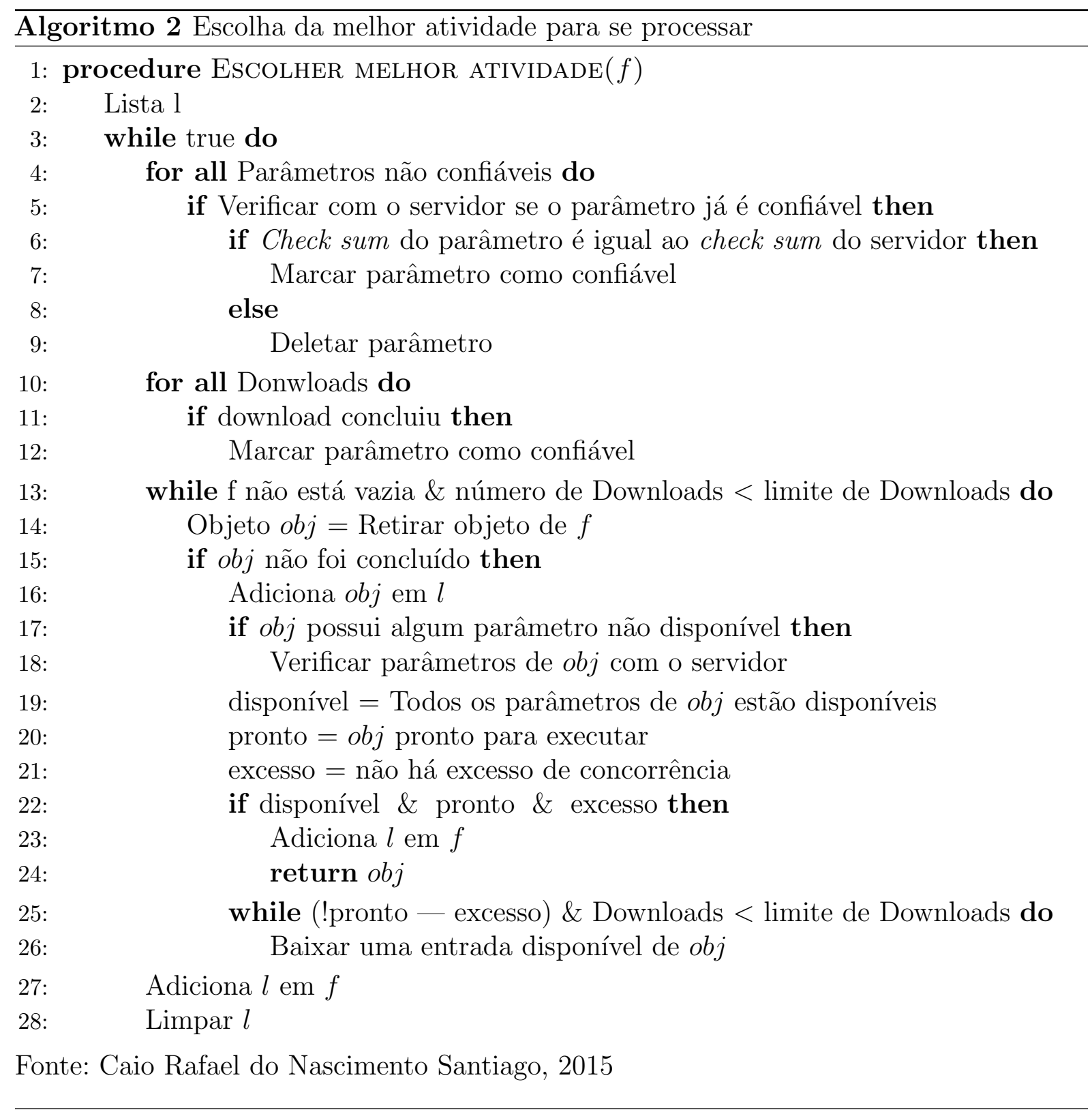

Depois de escolhida a atividade, resta baixar as informações a serem processadas. No momento em que a atividade começa a ser processada também se inicia (em paralelo) um processamento similar à função Escolher melhor atividade. Esse processamento (chamado no algoritmo como Segundo Plano) começa a preparar futuras atividades para serem processadas assim que a atividade atual terminar, a única diferença é que esse processamento não inicia a execução de uma atividade. 


\subsection{Considerações Finais}

Neste capítulo foi apresentada a solução desenvolvida neste trabalho, um sistema de computação voluntária que aplica técnicas de computação P2P. Os voluntários se comunicam entre si a fim de trocarem dados dos parâmetros enquanto estão ocupados processando as atividades. O objetivo disso é utilizar a banda de transmissão de dados dos voluntários para diminuir uma potencial sobrecarga de requisições ao servidor.

Para alcançar o objetivo deste projeto, foi necessário utilizar um SGW, descrito na Seção 2.7, e modificá-lo para facilitar a modularização dos componentes, permitindo assim ao SGW trabalhar com diferentes métodos de escalonamento. 


\section{AVALIAÇÃO DA SOLUÇÃO E RESULTADOS}

Neste Capítulo estão descritos os mecanismos utilizados para avaliar o desempenho da solução desenvolvida. Foram definidos os recursos de hardware e software utilizados para a execução de dois conjuntos de testes. O primeiro conjunto utiliza o workflow de um problema real de análise e rede sociais. Já o segundo o segundo utiliza exemplos simplificados de estruturas básicas de workflows que formam descritas na seção 2.6. Em seguida são descritos e discutidos os resultados obtidos.

\subsection{Avaliação da Solução}

A seguir são apresentadas as configurações (de infraestrutura, software e estudo de caso) utilizadas nos testes realizados.

Foram utilizados ao todo quatro computadores (notebooks), com as configurações definidas na tabela 3. Todos os computadores foram conectados em um roteador Wireless e tiveram suas larguras de banda limitadas via software. Para a execução do sistema foi necessária a instalação de Java@ em todos os computadores (em conjunto com algumas bibliotecas). Adicionalmente foi necessária a instalação de um programa para realizar a limitação de banda via software, para isto foi utilizado o trickle ${ }^{1}$, um programa para Linux que limita a banda de um determinado processo.

Tabela 3 - Configurações do computadores utilizados

\begin{tabular}{cccccc}
\hline$\#$ & Processador & \# Threads & Clock & Memória & S.O. \\
\hline 1 & Intel@Core i5-3230M & 4 & $3.20 \mathrm{GHz}$ & $8 \mathrm{~GB}$ & Ubuntu 14.04 \\
2 & Intel@Core i3-350M & 4 & $2.26 \mathrm{GHz}$ & $4 \mathrm{~GB}$ & Ubuntu 14.04 \\
3 & Intel@Pentium T3400 & 2 & $2.26 \mathrm{GHz}$ & $3 \mathrm{~GB}$ & Ubuntu 12.04 \\
4 & Intel@Core 2 Duo T5750 & 2 & $2.00 \mathrm{GHz}$ & $2 \mathrm{~GB}$ & Ubuntu 12.04 \\
\hline
\end{tabular}

Fonte: Caio Rafael do Nascimento Santiago, 2015

As velocidades de conexão foram limitadas com o intuito de simular as condições reais de conexões com a internet, por isso foram utilizadas como base as velocidades médias das conexões brasileiras (2,4 Mbps de download)(AKAMAI, 2013), infelizmente não foi possível encontrar as velocidades médias de upload, portanto foi assumido que as taxas de

1 https://wiki.archlinux.org/index.php/Trickle 
upload são de $10 \%$ das taxas de download (relação utilizada pelas operadoras de Internet brasileiras).

Em cada um dos casos de teste realizados também foram comparados os impactos da redundância dos resultados das atividades. Para verificar a veracidade de um resultado o sistema pode exigir que a mesma atividade seja executada $n$ vezes. Para os testes com redundância, exigiu-se que cada resultado seja produzido apenas duas vezes.

Todos os casos de teste apresentados foram comparados em três diferentes situações. Na primeira, a execução é totalmente local, utilizando o computador 1, o computador mais potente entre os disponíveis, e sendo processada uma atividade de cada vez. A segunda e a terceira situações são, respectivamente, a computação voluntária e a solução aplicando técnicas de P2P. Ambas utilizando o computador 4 como servidor e os demais como voluntários. Em todos os testes nunca foi solicitado a um voluntário que executasse mais de uma atividade ao mesmo tempo (no máximo o voluntário poderia estar executando uma atividade enquanto baixa parâmetros de outro). Apesar de ser facilmente configurável no sistema a solicitação de execução de várias atividades simultâneas nos voluntários, optou-se por não fazer isto para diminuir o número de variáveis evolvidas nos testes.

As próximas subseções descrevem os dois casos de testes utilizados.

\subsubsection{Caso de Teste Baseado em Análise de Redes Sociais}

O primeiro caso de teste é baseado em um workflow real de análise de redes sociais (DIGIAMPIETRI; SANTIAGO; ALVES, 2013; DIGIAMPIETRI et al., 2014a) e é apresentado, como pode ser visto na figura 8. Antes de mais nada dois itens devem ser esclarecidos. Primeiro, os pequenos círculos azuis sobre as atividades representam parâmetros que não são saídas de nenhuma atividade, são dados pelo projetista do workflow e estão disponíveis desde o início da execução. Segundo, as atividades com fundo azul podem ser executadas localmente independente de qual método de escalonamento seja escolhido, isto é, mesmo que os testes sejam realizados utilizando a computação voluntária as atividades podem ser processados localmente, e neste caso serão testadas e analisadas as duas condições (com e sem a execução local destas atividades). No SGW desenvolvido, ficou a cargo do projetista determinar se uma atividade poderá ou não ser utilizada no servidor. Na versão atual do sistema, por padrão, as atividades são configuradas para não serem executadas no servidor visando a não onerar o processamento do servidor, especialmente imaginando situações 
nas quais muitos workflows estariam executando ao mesmo tempo. Porém, como dito, o projetista pode habilitar a execução de atividades específicas no servidor.

Figura 8 - Workflow de teste baseado em um problema real de análise de redes sociais

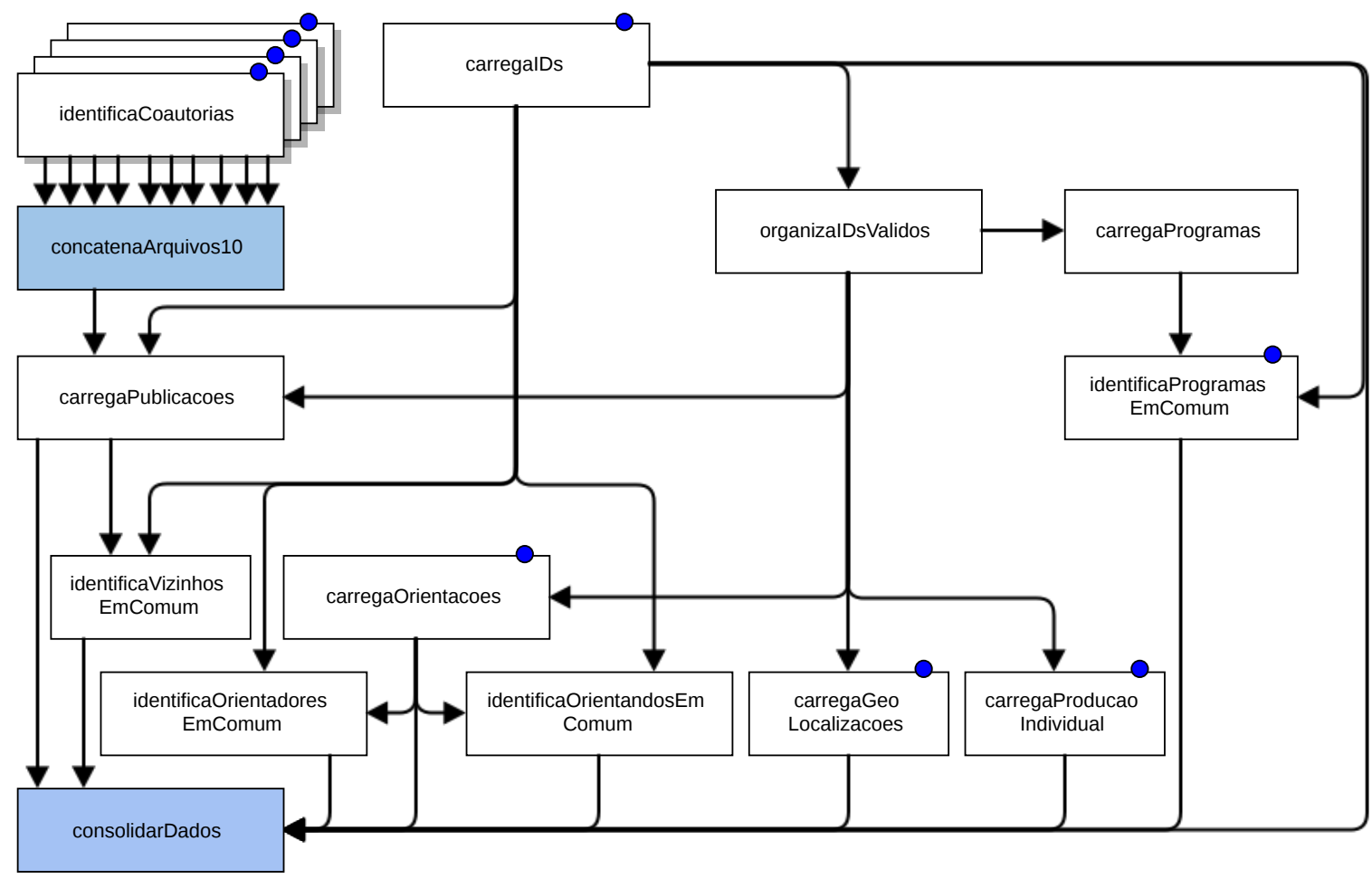

Fonte: Caio Rafael do Nascimento Santiago, 2015

O objetivo do workflow da figura 8 é produzir um conjunto de atributos ou características para serem utilizados no processo de predição de coautorias em redes acadêmicas (DIGIAMPIETRI; SANTIAGO; ALVES, 2013; DIGIAMPIETRI et al., 2014a). Estas características são calculadas para cada par de pesquisadores e serão utilizadas para tentar predizer se um dado par de pesquisadores irá ou não colaborar na publicação de um artigo. Para isto são utilizadas diferentes informações oriundas dos currículos da plataforma Lattes (por exemplo, lista de publicações de cada pesquisador, lista de orientações, endereço profissional). Os dados utilizados nos testes são de 657 pesquisadores que são orientadores permanentes em programas de pós-graduação na área de Ciência da Computação. De maneira resumida, o workflow funciona da seguinte maneira. A maioria das atividades é responsável por produzir os dados referentes a alguma das características que será utilizada posteriormente (fora do presente workflow) para a predição de coautorias. Por exemplo, as dez instâncias da atividade identificaCoautorias são chamadas cada uma recebendo 
um arquivo de entrada que corresponde a um subconjunto da lista total de publicações de cada um dos pesquisadores, os resultados destas atividades são concatenados pela atividade concatenaArquivos10. O resultado é utilizado para identificar a característica número de vizinhos em comuns pela atividade identificaVizinhosEmComum (considerando uma rede de coautorias). Outra característica que é calculada é se o par de pesquisadores possui orientandos em comum (atividade identificaOrientandosEmComum). Por fim, as diversas características calculadas são agrupadas pela atividade consolidarDados. O resultado desta atividade pode ser lido utilizado como entrada para um algoritmo de predição (DIGIAMPIETRI; SANTIAGO; ALVES, 2013).

Os parâmetros das 10 atividades identificaCoautorias são os que possuem maior volume de dados (alguns MBs), sendo que o maior possui 6,5 MBs. O restante dos parâmetros fornecidos pelo projetista também possuem um maior volume de dados do que seus derivados (os resultados parciais das atividades). Os dados trafegados são relativamente pequenos, mas possuem tamanho suficiente para, em situações de alta concorrência e/ou baixa velocidade, causar congestionamento na rede. Já as classes Java (cujas funções correspondem às atividades) são bastante pequenas, possuindo no máximo $20 \mathrm{KBs}$.

Cada caso foi executado três vezes, pois a diferença de desempenho entre os computadores e a diferença de processamento entre as atividades afeta a questão do balanceamento dos computadores, o que dificulta a verificação de resultados únicos. Portanto os resultados apresentados correspondem aos valores médios dessas execuções.

\subsubsection{Caso de Teste Baseado em Exemplos Simplificados}

Foram realizados outros testes baseados nas estruturas básicas de Workflows apresentadas em (BHARATHI et al., 2008) e discutida na Seção 2.6. Ao todo são quatro estruturas: Data Aggregation, Data Distribution, emphData Redistribution e Pipeline.

Cada estrutura foi testada isoladamente, isso é, cada caso de teste se limitou a um único tipo de estrutura, e todas utilizaram a mesma forma com exatamente o mesmo número de atividades representadas na figura 1, exibida na Seção 2.6.

Duas situações foram analisadas: na primeira os testes foram formados com apenas uma estrutura; na segunda os teste continham um conjunto de 10 estruturas iguais, mas independentes entre si (por exemplo, para o teste do Pipeline ao invés de um workflow com uma única sequência de atividades, foi também criado um workflow com 10 sequências 
destas atividades). O objetivo destas duas situações é verificar o impacto de atividades dependentes quando os voluntários podem ou não processar outras atividades disponíveis.

As atividades utilizadas nestes casos de teste foram atividades de exemplo, que realizam um mesmo processamento (apenas para simular um processamento intenso). $\mathrm{O}$ processamento realizado por elas faz a verificação do problema clássico $3 n+1$ (LAGARIAS, 1985) para o intervalo de 1 a 500.000.000, portanto a diferença nos tempos de execução de cada instância da atividade se deve apenas às diferenças de capacidade dos computadores. Além disso, os dados de entrada e saída também foram definidos com tamanhos constantes, de 2 MBs (vale destacar que a atividade utilizada nestes testes, na prática, não precisaria de entrada [por estarmos usando um intervalo constante de valores] e a saída poderia ser apenas um verdadeiro ou falso indicando que para o intervalo fixo utilizado a conjectura foi ou não confirmada, porém, estes parâmetros com tamanho fixo foram utilizados para simular situações reais no qual dados de entrada são necessários antes da execução da atividade que produz dados de saída que serão utilizados pela atividade seguinte ou correspondem ao resultado final da execução do workflow).

\subsection{Resultados}

As subseções a seguir descrevem separadamente os resultados obtidos.

\subsubsection{Caso de Teste Baseado em Análise de Rede Sociais}

Os resultados da aplicação de técnicas de computação P2P foram bastante positivos. As execuções foram mais rápidas quando comparadas às outras soluções, como pode ser visto na tabela 4. A duração da execução da solução desenvolvida foram reduzidos para 94 e 90\% quando comparados com a computação voluntária tradicional.

Existem dois motivos principais para os tempos terem diminuído. O primeiro motivo é que não houve aumento de tempo de execução das atividades causado pelo processamento que acontece em segundo plano do processamento da atividade (foram comparados os tempo do computador 1 entre os 3 sistemas e não foram constatadas diferenças), não há concorrência por recursos, pois o processamento em segundo plano é bastante simples e se aproveita da existência de mais de um núcleo no processador para não concorrer com o processamento da atividade em execução. O segundo motivo é que o comportamento 
Tabela 4 - Tempo de duração do processamento dos casos de testes reais de análise de redes sociais

\begin{tabular}{cccc}
\hline \multicolumn{2}{c}{ Execução } & Duração (tempo) & Duração $\frac{C V c o m P 2 P}{X}$ \\
\hline Local & & $7: 27: 19$ & $59 \%$ \\
\hline \multirow{2}{*}{ Com execução local } & CV & $04: 36: 31$ & $94 \%$ \\
& CV com P2P & $04: 22: 19$ & $100 \%$ \\
\hline \multirow{2}{*}{ Sem execução local } & CV & $04: 57: 00$ & $90 \%$ \\
& CV com P2P & $04: 27: 45$ & $100 \%$ \\
\hline
\end{tabular}

Fonte: Caio Rafael do Nascimento Santiago, 2015

proativo do escalonamento local prepara as atividades para serem processadas enquanto se processa a atividade anterior. A maioria das atividades já estavam prontas para serem processadas no momento em que foram escolhidas pelo escalonador local, reduzindo o tempo que o cliente demora baixando parâmetros antes de iniciar o processamento da atividade.

A tabela 5 apresenta o tempo médio gasto pelos voluntários apenas com transferências de dados, isto é, sem que o voluntário estivesse processando algum atividade (não foi considerado o tempo ocioso quando não havia atividades disponíveis para se processar). Na média, o tempo gasto com transferência foi reduzido em 30 e 31\%. As transferências correspondem a 26,7\% do tempo total de execução para o uso de computação voluntária tradicional e 13,8\% para o caso da computação voluntário utilizando P2P. Os valores da computação voluntária com P2P refletem, em grande parte, o tempo que o voluntário leva para baixar os parâmetros da primeira atividade que irá executar, já que no momento que as atividades subsequentes estão disponíveis para a execução, o voluntário já baixou a maior parte de seus parâmetros. O menor tempo de espera, por exemplo, no caso do Pipeline é justificada pelo fato de, na solução implementada, se o computador voluntário terminou a execução de uma atividade e continua disponível para a execução de outras ele já possui a saída da atividade que acabou de executar e então está pronto para executar a atividade subsequente (a próxima do Pipeline não precisando assim gastar tempo copiando parâmetros). Para o caso da computação voluntária tradicional, o voluntário devolverá primeiro a saída para o servidor e só depois se voluntariará para a execução de novas atividades.

Os voluntários acabam baixando mais parâmetros do que o necessário, isso porque não há como saber no momento do donwload se a atividade ainda estará disponível 
Tabela 5 - Tempo médio de espera transferindo dados nos voluntários nos casos de teste de análise de redes sociais

\begin{tabular}{cccc}
\hline \multicolumn{2}{c}{ Execução } & Duração (tempo) & Duração $\frac{C V \operatorname{comP2P}}{X}$ \\
\hline \multirow{2}{*}{ Com execução local } & CV & $00: 26: 07$ & $70 \%$ \\
& CV com P2P & $00: 18: 27$ & $100 \%$ \\
\hline \multirow{2}{*}{ Sem execução local } & CV & $00: 28: 19$ & $69 \%$ \\
& CV com P2P & $00: 19: 48$ & $100 \%$ \\
\hline
\end{tabular}

Fonte: Caio Rafael do Nascimento Santiago, 2015

para ser processada quando o voluntário for efetivamente escolher a próxima atividade para processar (a atividade pode já ter sido concluída ou já ter voluntários o suficiente a processando). Neste caso de teste praticamente todos os parâmetros são enviados para todos os voluntários. Sem a aplicação de técnicas de P2P o tráfego total seria aproximadamente três vezes maior que a computação voluntária, se for considerado apenas o tráfego de upload do servidor. Porém o total apresentou menos que o dobro da computação voluntária (entre 43 e $53 \%$ de aumento), como pode-se verificar na tabela 6. Nota-se que nos casos em que os parâmetros são mais reutilizados, aqueles em que os voluntários executam as atividades azuis (sem execução local), não há um crescimento muito maior na transferência de dados.

Tabela 6 - Dados transferidos por cada voluntário em MBs no caso real de redes sociais

\begin{tabular}{|c|c|c|c|c|c|c|c|c|c|}
\hline \multirow{2}{*}{ Execução } & \multicolumn{2}{|c|}{ Servidor } & \multicolumn{2}{|c|}{ Voluntário 1} & \multicolumn{2}{|c|}{ Voluntário 2} & \multicolumn{2}{|c|}{ Voluntário 3} & \multirow{2}{*}{$\begin{array}{l}\text { Up. Servidor } \\
\frac{C V \text { comP } 2 P}{X} \\
\end{array}$} \\
\hline & Up. & Down. & Up. & Down. & Up. & Down. & Up. & Down. & \\
\hline \multicolumn{10}{|c|}{ Com execução local } \\
\hline $\mathrm{CV}$ & 64,29 & 13,28 & 5,79 & 24,21 & 3,45 & 22,40 & 3,94 & 21,25 & $143 \%$ \\
\hline $\mathrm{CV}$ com $\mathrm{P} 2 \mathrm{P}$ & 91,95 & 15,25 & 4,91 & 28,91 & 7,20 & 27,69 & 2,98 & 33,10 & $100 \%$ \\
\hline \multicolumn{10}{|c|}{ Sem execução local } \\
\hline $\mathrm{CV}$ & 75,54 & 15,01 & 4,14 & 31,63 & 5,59 & 25,04 & 5,66 & 23,21 & $153 \%$ \\
\hline $\mathrm{CV}$ com $\mathrm{P} 2 \mathrm{P}$ & 115,74 & 17,92 & 6,30 & 38,29 & 6,74 & 37,70 & 5,00 & 38,82 & $100 \%$ \\
\hline
\end{tabular}

Fonte: Caio Rafael do Nascimento Santiago, 2015

A situação dos dados transferidos entre computadores se inverte quando consideramos a redundância de resultados, uma situação muito comum em sistemas de computação 
voluntária. Cada atividade foi processada duas vezes (utilizando-se voluntários diferentes) e os casos de teste utilizados são os que não executavam nenhuma atividade no servidor. A computação voluntária demorou pouco mais de oito horas e meia (08:33:30) e a aplicação de P2P 08:15:02 (representando uma economia de tempo de apenas 3,5\%). Porém, quanto a questão de dados transferidos (Tabela 7) pode-se notar que os valores para a computação voluntária praticamente dobrou (quando comparados com os testes sem redundância) enquanto que para a aplicação de P2P estes valores se mantiveram praticamente inalterados.

Tabela 7 - Dados transferidos por cada voluntário em MBs no caso real de redes sociais sem a execução de atividades no servidor (com redundância)

\begin{tabular}{cccccccccc}
\hline \multirow{2}{*}{ Execução } & \multicolumn{2}{c}{ Servidor } & \multicolumn{2}{c}{ Voluntário 1 } & \multicolumn{2}{c}{ Voluntário 2 } & \multicolumn{2}{c}{ Voluntário 3 } & \multicolumn{2}{c}{ Up. Servidor } \\
& Up. & Down. & Up. & Down. & Up. & Down. & Up. & Down. & $\frac{\text { CVcomP2P }}{X}$ \\
\hline CV & 153,31 & 30,18 & 9,41 & 64,15 & 11,26 & 54,65 & 10,22 & 38,38 & $64 \%$ \\
CV com P2P & 99,39 & 31,33 & 7,12 & 23,71 & 14,76 & 42,62 & 10,17 & 29,85 & $100 \%$ \\
\hline
\end{tabular}

Fonte: Caio Rafael do Nascimento Santiago, 2015

É possível também observar que a aplicação de P2P resultou em um melhor aproveitamento do processamento, a figura 9 apresenta a porcentagem de processamento em um caso de teste com o voluntário 1 e o servidor (vale lembrar que os testes foram realizados com três voluntários, mas para facilitar a leitura da figura 9 foram representados apenas a porcentagem de uso de processamento do servidor e de um voluntário já que o comportamento dos voluntários foi bastante semelhante). Para os dois casos (computação voluntária e computação voluntária com P2P) o servidor manteve, na média, baixíssimas taxas de processamento, abrindo a possibilidades de aproveitar o servidor para também executar atividades assim como os voluntários, ou realizar qualquer outro tipo de processamento, ou mesmo hospedar outros projetos de computação voluntária. Quanto aos voluntários existem dois comportamentos: a computação voluntária tradicional apresentou uma oscilação na curva de processamento, as "quedas" na curva representam os pontos em que uma atividade concluiu, baixou os parâmetros necessários, e começou o processamento da próxima atividade; e no caso com P2P não há essas "quebras" na curva já que o tempo entre as atividades foi minimizado. 
Figura 9 - Utilização do processamento dos testes baseados em um problema real de análise de redes sociais



Fonte: Caio Rafael do Nascimento Santiago, 2015

O uso de memória foi bastante similar entre as duas soluções. Os servidores da computação voluntária sem e com a aplicação de P2P utilizaram até, respectivamente, $4,9 \%$ e 7,4\%. Enquanto que os voluntários utilizaram até $9 \%$ e 7,4\%, respectivamente.

\subsubsection{Caso de Teste Baseado em Exemplos Simplificados}

Inicialmente, serão analisados os resultados dos testes contendo apenas uma estrutura. Os tempos de execução (Tabela 8) mostram que nestas condições o resultados da computação local obteve os melhores resultados para todos os casos, seguida pela solução desenvolvida neste trabalho, e a computação voluntária tradicional com os piores resultados (exceto na estrutura Data Distribution no qual o tempo das duas últimas soluções foi bastante parecido). Existe uma combinação de fatores que corrobora para esta situação: o computador que realiza a computação local é o mais rápido entre os três; tanto a computação voluntária tradicional quanto a modificação proposta neste trabalho são fortemente dependentes da existência de atividades paralelas, que não estão massivamente presentes neste caso. Em particular o número relativamente pequeno de atividades (algumas podendo ser processadas de maneira paralela e outras não), combinado com os custos relativamente altos de transferência de dados entre o servidor e os voluntários (de acordo com as configurações de taxas de transmissão de dados apresentadas no início deste capítulo) e, como já apresentado, nos testes de execução local, foi utilizado o melhor computador para executar todas as atividades. 
Tabela 8 - Tempo de duração do processamento dos casos de testes exemplos simplificados (com uma estrutura)

\begin{tabular}{cccc}
\hline Estrutura & Execução & Duração (tempo) & Duração $\frac{C V \operatorname{comP2P}}{X}$ \\
\hline \multirow{3}{*}{ Data Agregation } & Local & $0: 21: 55$ & $173 \%$ \\
& $\mathrm{CV}$ & $0: 39: 04$ & $97 \%$ \\
& P2P & $0: 38: 06$ & $100 \%$ \\
\hline \multirow{3}{*}{ Data Distribution } & Local & $0: 21: 37$ & $120 \%$ \\
& $\mathrm{CV}$ & $0: 25: 43$ & $101 \%$ \\
& $\mathrm{P} 2 \mathrm{P}$ & $0: 25: 59$ & $100 \%$ \\
\hline \multirow{3}{*}{ Data Redistribution } & Local & $0: 39: 33$ & $126 \%$ \\
& $\mathrm{CV}$ & $0: 58: 48$ & $85 \%$ \\
& P2P & $0: 50: 07$ & $100 \%$ \\
\hline \multirow{2}{*}{ Pipeline } & Local & $0: 15: 19$ & $132 \%$ \\
& $\mathrm{CV}$ & $0: 37: 31$ & $54 \%$ \\
& $\mathrm{P} 2 \mathrm{P}$ & $0: 20: 18$ & $100 \%$ \\
\hline
\end{tabular}

Fonte: Caio Rafael do Nascimento Santiago, 2015

A diferença de capacidade de processamento entre os computadores causou uma situação na qual, em alguns casos, computadores mais lentos estão processando atividades enquanto que os computadores mais rápidos, e portanto mais aptos, estão ociosos. Quando não há muitas atividades paralelas o tempo total da execução pode ficar dependente do tempo de execução pelo computador mais lento, prejudicando o desempenho total do sistema. A exposição deste caso pode ser vista na figura 10 que mostra quando os computadores estão ativos ou ociosos em função do tempo.

Esta situação não se beneficia dos pontos positivos da solução desenvolvida (em relação a solução local), mas mesmo nesta situação não favorável a solução proposta apresentou melhoras significativas na maiorias dos casos em relação à computação voluntária tradicional. O algoritmo de escalonamento proposto baixa outros parâmetros para processar as próximas atividades e, portanto, a primeira atividade nunca se beneficia desta estratégia. Além disso, como pode-se notar na figura 10 nestes testes há várias situações em que os voluntários estão processando uma atividade e não há mais nenhum parâmetro disponível para ser baixado.

Quanto a questão de tráfego de dados, os resultados foram muito próximos, como pode-se ver na tabela 9 . Novamente a questão de não haver parâmetros disponíveis para baixar no momento de processamento influenciou este caso. Os resultados do Data Distribution 
Figura 10 - Processamento em função do tempo (segundos) de cada voluntário no caso de exemplos simplificados (com uma estrutura)

(a) Data Aggregation em CV com P2P

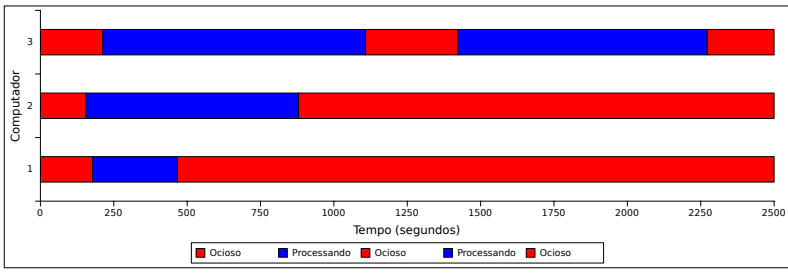

(c) Data Distribution em CV

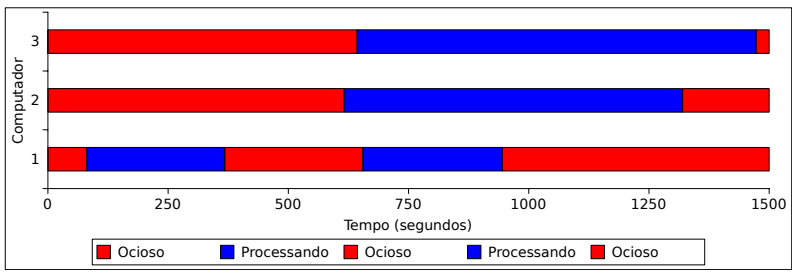

(e) Data Redistribution em CV com P2P

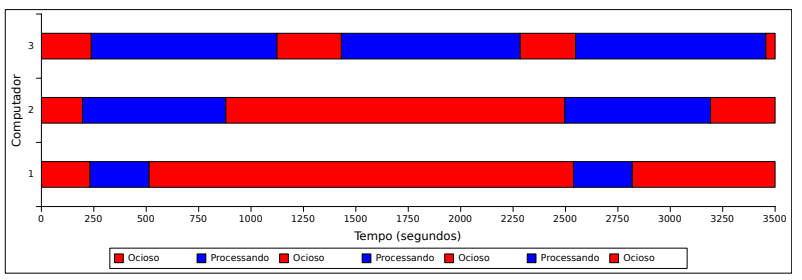

(g) Pipeline em CV

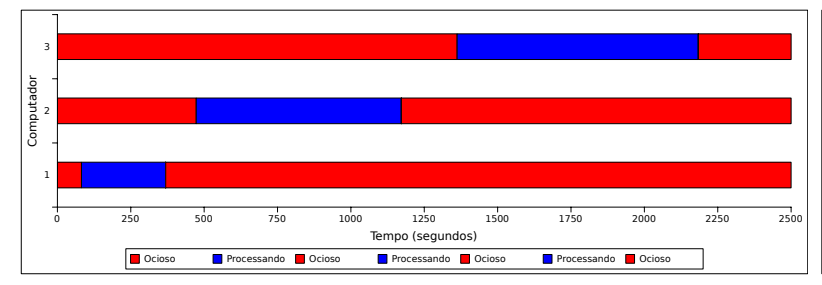

(b) Data Aggregation em CV com P2P

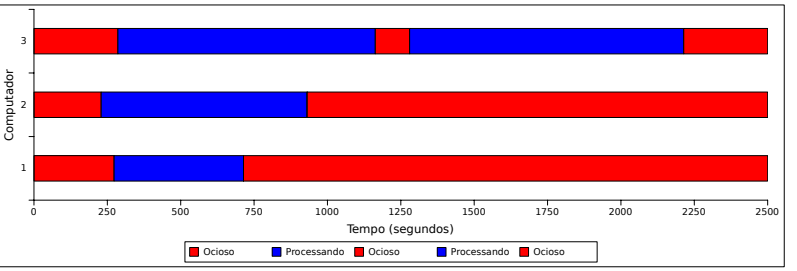

(d) Data Distribution em CV com P2P

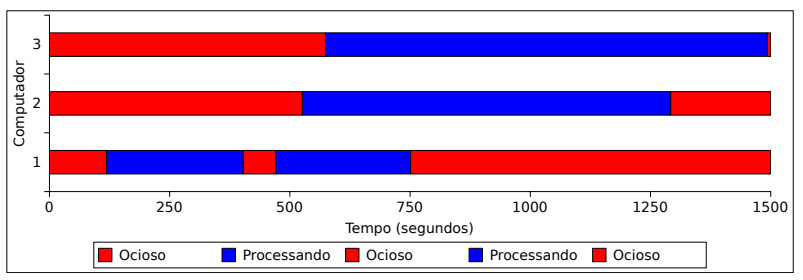

(f) Data Redistribution em CV com P2P

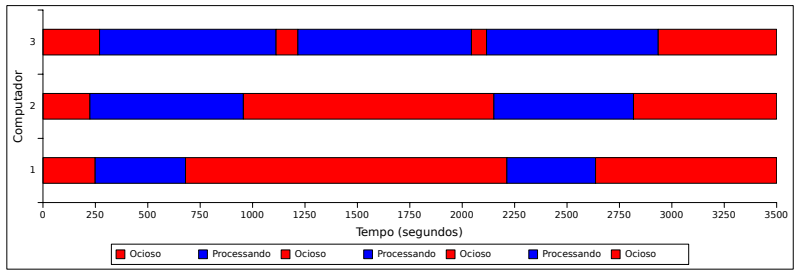

(h) Pipeline em CV com P2P



Fonte: Caio Rafael do Nascimento Santiago, 2015

e do Pipeline foram bastante próximos. O Data Aggregation e o Data Redistribution foram melhores, os resultados são modestos, mas proporcionalmente são resultados relevantes.

Já nos caso em que os teste continham um conjunto de 10 estruturas iguais e independentes os resultados foram mais promissores e serão discutidos a seguir. Notem que este tipo de caso de teste ajuda a ilustrar o comportamento do sistema imaginando-se tanto a execução de workflows mais complexos, mas também como o sistema se comportaria no caso da execução de 10 workflows (simples) ao mesmo tempo.

Assim como nos casos de teste utilizando o workflow de análise de redes sociais, para os exemplos simplificados com conjunto de estruturas (ver subseção 5.1.2), a computação voluntária com P2P se mostrou mais rápida, os tempos estão presentes na tabela 10. 
Tabela 9 - Dados transferidos por cada voluntário em MBs no caso de exemplos simplificados (com uma estrutura)

\begin{tabular}{|c|c|c|c|c|c|c|c|c|c|}
\hline \multirow{2}{*}{ Execução } & \multicolumn{2}{|c|}{ Servidor } & \multicolumn{2}{|c|}{ Voluntário 1} & \multicolumn{2}{|c|}{ Voluntário 2} & \multicolumn{2}{|c|}{ Voluntário 3} & \multirow{2}{*}{$\begin{array}{l}\text { Up. Servidor } \\
\frac{C V \operatorname{com} P 2 P}{X}\end{array}$} \\
\hline & Up. & Down. & Up. & Down. & Up. & Down. & Up. & Down. & \\
\hline \multicolumn{10}{|c|}{ Data Aggregation } \\
\hline $\mathrm{CV}$ & 12,57 & 8,60 & 2,04 & 2,00 & 2,12 & 2,22 & 4,34 & 8,61 & $82 \%$ \\
\hline $\mathrm{CV}$ com $\mathrm{P} 2 \mathrm{P}$ & 10,43 & 8,51 & 2,30 & 6,12 & 2,21 & 5,10 & 3,96 & 2,86 & $100 \%$ \\
\hline \multicolumn{10}{|c|}{ Data Distribution } \\
\hline $\mathrm{CV}$ & 8,49 & 8,35 & 3,75 & 3,78 & 2,14 & 2,15 & 2,11 & 2,18 & $101 \%$ \\
\hline $\mathrm{CV}$ com $\mathrm{P} 2 \mathrm{P}$ & 8,63 & 8,38 & 3,77 & 2,07 & 2,20 & 3,13 & 2,15 & 3,22 & $100 \%$ \\
\hline \multicolumn{10}{|c|}{ Data Redistribution } \\
\hline $\mathrm{CV}$ & 17,72 & 14,25 & 4,17 & 4,10 & 4,35 & 4,41 & 6,44 & 10,87 & $81 \%$ \\
\hline $\mathrm{CV}$ com $\mathrm{P} 2 \mathrm{P}$ & 14,41 & 14,63 & 4,15 & 6,70 & 4,50 & 4,58 & 2,78 & 2,88 & $100 \%$ \\
\hline \multicolumn{10}{|c|}{ Pipeline } \\
\hline $\mathrm{CV}$ & 6,17 & 6,23 & 1,82 & 1,84 & 2,11 & 2,15 & 2,13 & 2,25 & $106 \%$ \\
\hline $\mathrm{CV}$ com $\mathrm{P} 2 \mathrm{P}$ & 6,57 & 6,22 & 5,69 & 2,03 & 0,11 & 2,15 & 0,12 & 2,26 & $100 \%$ \\
\hline
\end{tabular}

Fonte: Caio Rafael do Nascimento Santiago, 2015

Pode-se notar que os tempos foram consideravelmente mais baixos, mas como todas as atividades são iguais os tempos são mais constantes (do que no estudo de caso real). A comparação desta relação de tempo entre a computação voluntária tradicional e utilizando computação P2P mostra uma variação de $75 \%$ a $87 \%$ e, novamente, essa variação é causada pela diminuição do tempo para se obter os parâmetros.

Tabela 10 - Tempo de duração do processamento dos casos de testes exemplos simplificados (com 10 estruturas)

\begin{tabular}{cccc}
\hline Estrutura & Execução & Duração (tempo) & Duração $\frac{C V \text { comP2P }}{X}$ \\
\hline \multirow{3}{*}{ Data Agregation } & Local & $3: 49: 56$ & $62 \%$ \\
& CV & $3: 09: 50$ & $75 \%$ \\
& P2P & $2: 22: 37$ & $100 \%$ \\
\hline \multirow{3}{*}{ Data Distribution } & Local & $3: 06: 35$ & $79 \%$ \\
& CV & $2: 51: 00$ & $87 \%$ \\
& P2P & $2: 29: 13$ & $100 \%$ \\
\hline \multirow{3}{*}{ Data Redistribution } & Local & $6: 50: 19$ & $61 \%$ \\
& CV & $5: 04: 07$ & $83 \%$ \\
& P2P & $4: 12: 43$ & $100 \%$ \\
\hline \multirow{2}{*}{ Pipeline } & Local & $2: 20: 45$ & $77 \%$ \\
& CV & $2: 20: 37$ & $77 \%$ \\
& P2P & $1: 48: 28$ & $100 \%$ \\
\hline
\end{tabular}

Fonte: Caio Rafael do Nascimento Santiago, 2015 
Pode-se notar pela tabela 11 que o tempo que os clientes gastaram apenas transferindo dados foi bastante reduzido, menos da metade em todos os casos. O gasto de tempo da computação voluntária com P2P se deve principalmente por causa do envio da resposta para o servidor, pois no momento de enviar a resposta para o servidor o cliente não realiza nenhuma outra tarefa. O efeito dessa redução de tempo com transferência de dados impacta diretamente no tempo total de execução dos casos, já que se foram descontados esse tempo sobre o tempo total de execução os resultados se aproximam.

Tabela 11 - Tempo médio de espera transferindo dados pelos voluntários nos casos de exemplos simplificados (com 10 estruturas)

\begin{tabular}{cccc}
\hline Estrutura & Execução & Duração (tempo) & Duração $\frac{C V \operatorname{comP2P}}{X}$ \\
\hline \multirow{2}{*}{ Data Aggregation } & $\mathrm{CV}$ & $00: 57: 55$ & $37 \%$ \\
& $\mathrm{P} 2 \mathrm{P}$ & $00: 21: 53$ & $100 \%$ \\
\hline \multirow{2}{*}{ Data Distribution } & $\mathrm{CV}$ & $00: 41: 37$ & $48 \%$ \\
& $\mathrm{P} 2 \mathrm{P}$ & $00: 20: 04$ & $100 \%$ \\
\hline \multirow{2}{*}{ Data Redistribution } & $\mathrm{CV}$ & $01: 25: 21$ & $37 \%$ \\
& $\mathrm{P} 2 \mathrm{P}$ & $00: 31: 49$ & $100 \%$ \\
\hline \multirow{2}{*}{ Pipeline } & $\mathrm{CV}$ & $00: 33: 24$ & $45 \%$ \\
& $\mathrm{P} 2 \mathrm{P}$ & $00: 15: 09$ & $100 \%$ \\
\hline
\end{tabular}

Fonte: Caio Rafael do Nascimento Santiago, 2015

Quanto às questões do tráfego de dados os resultados foram bastante positivos, diferente do caso de teste em redes sociais. Pode-se notar na tabela 12 que a aplicação de $\mathrm{P} 2 \mathrm{P}$ obteve resultados consideravelmente melhores, quando consideramos apenas o servidor que é justamente o foco desta abordagem. Quase todos os resultados obtiveram um total de upload abaixo da metade da computação voluntária tradicional e o principal motivo para a diferença entre os dois casos de testes é que no caso de análise de redes sociais as atividades possuíam saídas consideravelmente menores que suas entradas, já nestes casos ambas possuem o mesmo tamanho, o que favoreceu essa abordagem. Quanto ao total de download os valores foram muito próximos, mas a solução com P2P causou um cenário em que o servidor recebeu mais dados do que enviou. Receber mais do que enviar é tipicamente considerada uma coisa bastante positiva em muitos cenários reais (por exemplo, na estrutura da internet para usuários comuns, as operadoras garantam taxas de download bem maiores que as de upload), favorecendo novamente a abordagem proposta. 
Tabela 12 - Dados transferidos por cada voluntário em MBs no caso de exemplos simplificados (com 10 estruturas)

\begin{tabular}{|c|c|c|c|c|c|c|c|c|c|}
\hline \multirow{2}{*}{ Execução } & \multicolumn{2}{|c|}{ Servidor } & \multicolumn{2}{|c|}{ Voluntário 1} & \multicolumn{2}{|c|}{ Voluntário 2} & \multicolumn{2}{|c|}{ Voluntário 3} & \multirow{2}{*}{$\begin{array}{l}\text { Up. Servidor } \\
\frac{C V \operatorname{com} P 2 P}{X}\end{array}$} \\
\hline & Up. & Down. & Up. & Down. & Up. & Down. & Up. & Down. & \\
\hline \multicolumn{10}{|c|}{ Data Aggregation } \\
\hline CV & 120,68 & 82,38 & 37,27 & 60,17 & 25,66 & 30,57 & 20,74 & 34,10 & $62 \%$ \\
\hline $\mathrm{CV}$ com $\mathrm{P} 2 \mathrm{P}$ & 75,92 & 85,04 & 40,20 & 18,73 & 22,98 & 26,14 & 16,49 & 26,22 & $100 \%$ \\
\hline \multicolumn{10}{|c|}{ Data Distribution } \\
\hline $\mathrm{CV}$ & 84,64 & 84,28 & 37,48 & 37,57 & 25,72 & 26,63 & 18,37 & 19,14 & $40 \%$ \\
\hline $\mathrm{CV}$ com $\mathrm{P} 2 \mathrm{P}$ & 33,97 & 83,37 & 38,37 & 11,16 & 25,41 & 13,00 & 18,31 & 8,66 & $100 \%$ \\
\hline \multicolumn{10}{|c|}{ Data Redistribution } \\
\hline $\mathrm{CV}$ & 185,21 & 147,01 & 62,49 & 92,37 & 44,27 & 43,99 & 36,20 & 45,41 & $38 \%$ \\
\hline $\mathrm{CV}$ com $\mathrm{P} 2 \mathrm{P}$ & 71,02 & 143,72 & 63,14 & 19,98 & 42,48 & 24,51 & 34,86 & 27,28 & $100 \%$ \\
\hline \multicolumn{10}{|c|}{ Pipeline } \\
\hline $\mathrm{CV}$ & 61,79 & 61,29 & 26,85 & 26,75 & 18,91 & 19,41 & 14,21 & 15,25 & $45 \%$ \\
\hline $\mathrm{CV}$ com $\mathrm{P} 2 \mathrm{P}$ & 28,13 & 59,52 & 30,32 & 8,36 & 14,46 & 8,57 & 14,35 & 10,51 & $100 \%$ \\
\hline
\end{tabular}

Fonte: Caio Rafael do Nascimento Santiago, 2015

Na situação em que são exigidas duas execuções da mesma atividade (redundância), os resultados se mantêm bastante próximos aos casos de teste de rede sociais. Conforme pode ser observado na tabela 13, os tempos de execução foram consideravelmente mais rápidos, em uma proporção similar a que foi encontrada no mesmo caso sem redundância, como pode-se notar na tabela 14 .

Tabela 13 - Tempo de duração do processamento dos casos de testes exemplos simplificados (com 10 estruturas e redundância)

\begin{tabular}{cccc}
\hline Estrutura & Execução & Duração (tempo) & Duração $\frac{C V \operatorname{comP2P}}{X}$ \\
\hline \multirow{2}{*}{ Data Agregation } & $\mathrm{CV}$ & $7: 17: 01$ & $81 \%$ \\
& $\mathrm{P} 2 \mathrm{P}$ & $5: 56: 38$ & $100 \%$ \\
\hline \multirow{2}{*}{ Data Distribution } & $\mathrm{CV}$ & $6: 58: 02$ & $74 \%$ \\
& $\mathrm{P} 2 \mathrm{P}$ & $5: 13: 22$ & $100 \%$ \\
\hline \multirow{2}{*}{ Data Redistribution } & $\mathrm{CV}$ & $11: 14: 16$ & $77 \%$ \\
& $\mathrm{P} 2 \mathrm{P}$ & $8: 44: 02$ & $100 \%$ \\
\hline \multirow{2}{*}{ Pipeline } & $\mathrm{CV}$ & $5: 13: 39$ & $81 \%$ \\
& $\mathrm{P} 2 \mathrm{P}$ & $4: 15: 22$ & $100 \%$ \\
\hline
\end{tabular}

Fonte: Caio Rafael do Nascimento Santiago, 2015

Assim como no caso sem redundância, a banda utilizada pelo servidor também foi menor com a computação voluntária com P2P (Tabela 15) e o aumento da banda de 
Tabela 14 - Comparação entre o tempo de CV com o tempo da CV com P2P (com e sem redundância - 10 estruturas)

\begin{tabular}{|c|c|c|}
\hline Estrutura & $\begin{array}{c}\text { Duração (sem redundância) } \\
\frac{X}{C V \operatorname{com} P 2 P} \\
\end{array}$ & $\begin{array}{c}\text { Duração (com redundância) } \\
\frac{C V \operatorname{com} P 2 P}{X} \\
\end{array}$ \\
\hline Data Agregation & $75 \%$ & $81 \%$ \\
\hline Data Distribution & $87 \%$ & $74 \%$ \\
\hline Data Redistribution & $83 \%$ & $78 \%$ \\
\hline Pipeline & $77 \%$ & $81 \%$ \\
\hline
\end{tabular}

Fonte: Caio Rafael do Nascimento Santiago, 2015

upload foi relativamente baixo ao se comparar com o da computação voluntária tradicional (este último foi de aproximadamente 100\% em relação a situação sem redundância).

Tabela 15 - Dados transferidos por cada voluntário em MBs no caso de exemplos simplificados (com 10 estruturas e redundância)

\begin{tabular}{|c|c|c|c|c|c|c|c|c|c|}
\hline \multirow{2}{*}{ Execução } & \multicolumn{2}{|c|}{ Servidor } & \multicolumn{2}{|c|}{ Voluntário 1} & \multicolumn{2}{|c|}{ Voluntário 2} & \multicolumn{2}{|c|}{ Voluntário 3} & \multirow{2}{*}{$\begin{array}{l}\text { Up. Servidor } \\
\frac{C V \text { comP2P }}{X}\end{array}$} \\
\hline & Up. & Down. & Up. & Down. & Up. & Down. & Up. & Down. & \\
\hline \multicolumn{10}{|c|}{ Data Aggregation } \\
\hline CV & 243,28 & 167,59 & 75,72 & 113,37 & 49,73 & 70,50 & 43,52 & 66,35 & $33 \%$ \\
\hline CV com P2P & 80,29 & 165,71 & 65,30 & 20,80 & 44,60 & 23,73 & 44,99 & 31,59 & $100 \%$ \\
\hline \multicolumn{10}{|c|}{ Data Distribution } \\
\hline $\mathrm{CV}$ & 168,12 & 165,18 & 76,21 & 75,33 & 46,86 & 47,34 & 41,01 & 44,19 & $21 \%$ \\
\hline $\mathrm{CV}$ com $\mathrm{P} 2 \mathrm{P}$ & 35,77 & 164,07 & 69,75 & 10,32 & 46,21 & 11,90 & 42,00 & 11,75 & $100 \%$ \\
\hline \multicolumn{10}{|c|}{ Data Redistribution } \\
\hline CV & 372,88 & 293,27 & 132,15 & 168,38 & 81,50 & 98,83 & 71,88 & 101,33 & $23 \%$ \\
\hline $\mathrm{CV}$ com $\mathrm{P} 2 \mathrm{P}$ & 86,46 & 288,25 & 127,12 & 28,60 & 80,16 & 23,84 & 70,74 & 31,54 & $100 \%$ \\
\hline \multicolumn{10}{|c|}{ Pipeline } \\
\hline CV & 121,99 & 124,28 & 55,21 & 54,73 & 33,55 & 33,93 & 32,48 & 34,27 & $21 \%$ \\
\hline CV com P2P & 26,21 & 123,21 & 58,20 & 7,97 & 35,74 & 8,24 & 26,36 & 9,40 & $100 \%$ \\
\hline
\end{tabular}

Fonte: Caio Rafael do Nascimento Santiago, 2015

\subsection{Considerações Finais}

A solução desenvolvida neste trabalho e avaliada neste capítulo se mostrou bastante promissora, quando confrontada com os outros dois métodos de escalonamento: a computação voluntária tradicional e a execução local. Os resultados foram positivos para as configurações de teste utilizadas, isto é, os dois casos de testes com a infraestrutura de hardware definida. Nestas condições foram obtidas diminuições nos tempo de execução dos 
workflows e nas transferências de dados de servidor (no caso de redes sociais e nos casos com exemplos simplificados).

O primeiro caso de teste utilizou um workflow real da área de análise de redes sociais. A solução se mostrou mais rápida do que os outros dois métodos de escalonamento, tanto com e sem redundância, entre 3,5 e 10\% de melhora. A banda gasta pelo servidor registrou uma considerável piora relativa na situação sem redundância (entre 43 e 53\% de piora), o principal motivo para isso acontecer se deve ao fato dos dados trafegados inicialmente serem maiores que os dados resultantes da execução das atividades. Mas na situação com redundância a questão do gasto de banda se inverte e a solução desenvolvida se torna mais atraente: a computação voluntária tradicional exige mais tráfego de dados enquanto que a solução desenvolvida se mostra mais constante apresentando neste caso uma melhora em torno de $36 \%$.

O segundo caso de teste utilizou exemplos simplificados (toy examples) das estruturas básicas de workflows. Foram testados conjuntos com uma ou dez estruturas. Nos casos com uma estrutura os resultados foram equivalentes ou melhores que a computação voluntária tradicional, mas ambos foram inferiores a execução local de atividades. Isso se deve a alguns fatores: o computador utilizado na execução local foi o mais rápido entre os utilizados nos testes; as estruturas utilizadas possuíam um baixo poder de paralelização, isso causou algumas situações em que os voluntários ficaram ociosos por não haver atividades para se processar; e por último o tempo gasto com transferências de dados pesou contra os métodos de processamento distribuído. Enquanto que os resultados comparados com a execução local apresentou tempo entre 20 e $76 \%$ mais lento, os resultados comparado à computação voluntária foram no mínimo equivalentes ou até $45 \%$ mais rápidos, e consumiram até $19 \%$ menos banda de upload do servidor. Já no conjunto de 10 estruturas todos os resultados foram melhores que a execução local e a computação voluntária, entre 13 e 25\% mais rápidos (sem redundância, já com redundância a melhora foi de 19 a 26\%) e consumiu de 48 a $62 \%$ menos da banda de upload do servidor (sem redundância, já com redundância essa economia de banda aumenta para $67 \%$ a $79 \%$ ).

Os resultados apresentados para os teste realizados foram positivos e mostraram uma melhora quando comparados à computação voluntária tradicional. Foram obtidas melhoras no tempo total de execução e, com exceção no caso de redes sociais sem redundância, houve uma diminuição no consumo de banda de upload do servidor e nos tempos de processamento ocioso gastos com transferências de dados. Isso não garante que a solução 
sempre será melhor que a computação voluntária tradicional, como por exemplo, é possível que a solução seja pouco eficiente caso os parâmetros não sejam reutilizados. Além disso, a arquitetura completamente baseada em P2P, em que todos os voluntários se comunicam entre si, pode necessitar de mecanismos mais eficientes de comunicação e escalonamento quando escalada. 


\section{CONCLUSÕES}

Este trabalho se propôs a especificar, desenvolver e testar uma solução para a execução distribuída de workflows combinando computação voluntária e técnicas de computação ponto-a-ponto.

A principal ideia do projeto foi tentar aproveitar o momento em que os voluntários estavam com o processador ocupado executando atividades, mas inativos do ponto de vista de tráfego de dados para preparar as próximas atividades a serem processadas, bem como para auxiliar outros voluntários compartilhando parâmetros. Essa abordagem diminuiu o tempo em que o voluntário não está processando atividades (por estar copiando parâmetros) e diminui a exigência sobre a banda do servidor, sem aumentar o tempo que levaria para uma atividade ser processada em relação a uma abordagem convencional de computação voluntária.

A fim de atingir o objetivo proposto foi realizada uma revisão sistemática acerca de métodos de escalonamento de ambientes de computação voluntária que apliquem técnicas de computação P2P. A revisão encontrou poucos trabalhos relacionados com o tema, corroborando com a contribuição potencial deste trabalho. Os trabalhos foram analisados e suas características foram apontadas.

Em seguida foi especificado e desenvolvido um Sistema de Gerenciamento de Workflows (SGW) a partir de um sistema já existente, construído no decorrer do projeto Jovem Pesquisador em Centros Emergentes - FAPESP do orientador. O SGW foi reformulado e expandido para torná-lo mais modularizado e flexível o suficiente para utilizar diferentes tipos de técnicas de escalonamento. Neste trabalho formam desenvolvidos três métodos de escalonamento: considerando execução local, execução com computação voluntária tradicional e, a solução proposta, considerando computação voluntária utilizando técnicas P2P.

A solução proposta foi comparada com a execução local de atividades e com a computação voluntária tradicional. Os três métodos foram testados em dois cenários de testes, e a partir das métricas sobre os resultados obtidos foi constada a melhora de desempenho da solução proposta. Em ambos os cenários de teste, o caso real de análise de redes sociais e os conjuntos de exemplos simplificados de estruturas de workflows, foi possível obter métricas referentes ao tempo de execução, de transmissão de dados, de 
espera sem processamento e métricas referentes ao gasto/utilização de banda do servidor e dos voluntários. São resultados bastante positivos que mostram que a solução é capaz de diminuir o tempo total de uma execução e, em alguns casos, diminuir o gasto de banda do servidor.

A seguir, são apresentadas as principais contribuições deste trabalho e as propostas de trabalhos futuros.

\subsection{Principais Contribuições}

Este trabalho teve como principal objetivo e contribuição, a construção de um ambiente de computação voluntária funcional que utilizasse técnicas de computação P2P em seu escalonamento. O objetivo foi alcançado uma vez que o ambiente foi construído e obteve resultados superiores aos da computação voluntária tradicional nas questões da duração total da execução dos workflows e na exigência de largura de banda que foram ambos diminuídos

Além do objetivo principal deste trabalho também foram alcançadas outras contribuições, são elas:

- Uma revisão sistemática foi realizada e disponibilizada acerca do tema: métodos de escalonamento de ambientes de computação voluntária que utilizam técnicas de P2P. Esta revisão pode servir de base para trabalhos futuros correlatos.

- Foi construído um SGW correspondendo à extensão do SGW desenvolvido no Jovem Pesquisador em Centros Emergentes - FAPESP do orientador. O SGW foi original restruturado, tornando-o mais organizado e modularizado. O SGW resultante é totalmente funcional e possui três métodos de escalonamento implementados atualmente e pode ser facilmente ser modificado e expandido para trabalhar com outros métodos.

- Também foi construído um ambiente de computação voluntária totalmente funcional. O ambiente é capaz de executar remotamente, em computadores pessoais, funções desenvolvidas em Java. O ambiente se encarrega de enviar as classes e parâmetros necessários, tornando o trabalho do projetista do workflow bastante transparente. Apesar de não ser o foco deste trabalho, os serviços Web continuam podendo ser executados por atividades dos worklfows, pois, assim como na versão original do SGW, 
estes serviços são encapsulados por funções desenvolvidas em Java. Obviamente, a execução destes serviços não onera o processador do servidor ou do voluntário, porém, dependendo do volume de dados dos resultados intermediários das atividades, a solução proposta pode ser útil para uma melhor distribuição de banda.

- Dentro do ambiente de computação voluntária desenvolvido foi criado um algoritmo de escalonamento. O algoritmo está presente em todos os voluntários e se baseia em decisões locais. Os voluntários tornaram-se mais pró-ativos na buscar pelos parâmetros necessários para se processar as atividades, esse comportamento se torna mesmo oneroso para o servidor devido à aplicação de técnicas de P2P.

- O código fonte da solução desenvolvida, bem como dos testes executados, está disponível na web ${ }^{1}$ para poder ser utilizado tanto para execução de experimentos científicos, mas também como base para trabalhos futuros.

- Até o momento, a pesquisa deste mestrado foi parcialmente utilizada na publicação de quatro artigos. Três deles relacionados a partes da solução desenvolvida (DIGIAMPIETRI et al., 2013; DIGIAMPIETRI et al., 2014b; DIGIAMPIETRI et al., 2014) e um relacionado ao estudo de caso (DIGIAMPIETRI; SANTIAGO; ALVES, 2013).

\subsection{Trabalhos Futuros}

Durante o desenvolvimento do trabalho, foram identificadas diversas possibilidades de continuidade e evolução do ambiente desenvolvido, são elas:

1. Uma possível evolução deste trabalho seria abordar ambientes ainda mais heterogêneos, considerando os diferentes elementos, capacidades de processamento, velocidades de transmissão e graus de confiança dos resultados. Um exemplo deste conceito é a junção de diferentes tipos de workers no mesmo ambiente, por exemplo, como a junção de computadores voluntários e grids de diferentes naturezas.

2. A comunicação entre os voluntários, atualmente, não está pronta para diferentes tipos de conexões. Por exemplo, computadores com diferentes níveis de profundidade em rede NAT (Network Address Translation) podem encontrar dificuldade de se comunicarem. Este mecanismo, portanto, pode ser aprimorado para utilizar uma solução mais sofisticada e versátil.

$\overline{1}$ http://www.each.usp.br/digiampietri/codigos/codigos_crns.7z 
3. Os testes realizados utilizaram poucos computadores, não sendo possível assim saber como o método de escalonamento vai se comportar quando houver centenas ou milhares de voluntários. Assim, testes utilizando uma infraestrutura maior são desejáveis.

4. Também não foi testado o que acontece quando existe uma quantidade massiva de atividades, e nem quando muitos workflows são executados ao mesmo tempo. Apesar da solução desenvolvida apresentar, relativamente, um desempenho melhor do que a computação voluntária convencional nos exemplos em que um maior número de atividades foi executado, é interessante avaliar isto em exemplos ainda maiores.

5. Outra questão não verificada é como o ambiente se comporta com o aparecimento de falhas. Uma futura contribuição seria elaborar uma gestão eficiente de falhas, fazendo, por exemplo, uma estimativa da redundância necessária para cada atividade a ser executada bem como uma avaliação das melhores formas de detecção e tratamento das falhas.

6. A versão atual da solução desenvolvida não solicita a um voluntário a execução paralela de mais de uma atividade. Uma contribuição futura seria possibilitar que computadores voluntários com CPUs multi-núcleos executem várias atividades simultaneamente. 


\section{AGRADECIMENTOS}

O trabalho desenvolvido no decorrer deste mestrado foi financiado pela FAPESP (projetos 2013/07935-5 e 2009/10413-5). 


\section{Referências $^{2}$}

ACHARYA, A.; EDJLALI, G.; SALTZ, J. The utility of exploiting idle workstations for parallel computation. ACM SIGMETRICS Performance Evaluation Review, ACM, v. 25, n. 1, p. 225-234, jun. 1997. ISSN 01635999. Disponível em: <http://dl.acm.org/citation.cfm?id=258623.258691>. Citado na página 14.

AKAMAI. The State of the Internet. [S.1.], 2013. Citado na página 45.

ANDERSON, D. BOINC: a system for public-resource computing and storage. In: . [S.l.: s.n.], 2004. p. 4-10. Citado 4 vezes nas páginas 14, 20, 29 e 31.

ANDERSON, D. P. et al. SETI@home: an experiment in public-resource computing. Communications of the ACM, ACM, v. 45, n. 11, p. 56-61, nov. 2002. ISSN 00010782. Disponível em: <http://dl.acm.org/ft \_gateway.cfm?id=581573\\&type=html>. Citado na página 20.

ANDERSON, D. P.; FEDAK, G. The Computational and Storage Potential of Volunteer Computing. In: Cluster Computing and the Grid, 2006. CCGRID 06. Sixth IEEE International Symposium on. [S.l.: s.n.], 2006. v. 1, p. 73-80. Citado na página 14.

BARGA, R. S.; DIGIAMPIETRI, L. A. Automatic capture and efficient storage of e-Science experiment provenance. Concurrency and Computation: Practice and Experience, John Wiley \& Sons, Ltd., v. 20, n. 5, p. 419-429, 2008. ISSN 1532-0634. Disponível em: $<$ http://dx.doi.org/10.1002/cpe.1235>. Citado na página 24.

BEBERG, A. L. et al. Folding@home: Lessons from eight years of volunteer distributed computing. In: 2009 IEEE International Symposium on Parallel $\&$ Distributed Processing. IEEE, 2009. p. 1-8. ISBN 978-1-4244-3751-1. ISSN 1530-2075. Disponível em: $<$ http://ieeexplore.ieee.org/articleDetails.jsp?arnumber $=5160922>$. Citado na página 20.

BHARATHI, S. et al. Characterization of scientific workflows. In: 2008 Third Workshop on Workflows in Support of Large-Scale Science. IEEE, 2008. p. 1-10. ISBN 978-1-4244-2827-4. Disponível em: <http://ieeexplore.ieee.org/lpdocs/epic03/wrapper.htm?arnumber $=4723958>$. Citado 4 vezes nas páginas 16, 17, 22 e 48.

CELAYA, J.; ARRONATEGUI, U. Distributed Scheduler of Workflows with Deadlines in a P2P Desktop Grid. In: 2010 18th Euromicro Conference on Parallel, Distributed and Network-based Processing. IEEE, 2010. p. 69-73. ISBN 978-1-4244-5672-7.

ISSN 1066-6192. Disponível em: <http://ieeexplore.ieee.org/lpdocs/epic03/wrapper.htm?arnumber $=5452507>$. Citado 3 vezes nas páginas 28,32 e 34.

DETHIER, G. et al. LBG-SQUARE Fault-Tolerant, Locality-Aware Co-Allocation in P2P Grids. In: 2008 Ninth International Conference on Parallel and Distributed Computing, Applications and Technologies. IEEE, 2008. p. 252-258. ISBN 978-0-7695-3443-5. Disponível em: <http://ieeexplore.ieee.org/lpdocs/epic03/wrapper.htm?arnumber $=4710988>$.

Citado 2 vezes nas páginas 14 e 20.

2 De acordo com a Associação Brasileira de Normas Técnicas. NBR 6023. 
DIAS, J. et al. Improving Many-Task computing in scientific workflows using P2P techniques. In: 2010 3rd Workshop on Many-Task Computing on Grids and Supercomputers. IEEE, 2010. p. 1-10. ISBN 978-1-4244-9704-1. Disponível em: $<$ http://ieeexplore.ieee.org/lpdocs/epic03/wrapper.htm?arnumber $=5699430>$. Citado 2 vezes nas páginas 14 e 20.

DIGIAMPIETRI, L. et al. Análise da rede dos doutores que atuam em computação no brasil. In: $C S B C$-BraSNAM 2014. [S.l.: s.n.], 2014. Citado 2 vezes nas páginas 46 e 47.

DIGIAMPIETRI, L. et al. A framework for automatic composition of scientific experiments: Achievements, lessons learned and challenges. In: CSBC 2014 - BreSci. Brasília - DF: [s.n.], 2014. p. 315-322. Citado 2 vezes nas páginas 24 e 64.

DIGIAMPIETRI, L.; SANTIAGO, C.; ALVES, C. Predição de coautorias em redes sociais acadêmicas: um estudo exploratório em ciência da computação. In: CSBC-BraSNAM 2013. [S.l.: s.n.], 2013. Citado 4 vezes nas páginas 46, 47, 48 e 64.

DIGIAMPIETRI, L. et al. Um sistema de informação extensível para o reconhecimento automático de LIBRAS. In: SBSI 2012 - Trilhas Técnicas (Technical Tracks). [S.l.: s.n.], 2012. p. 12. Citado na página 24.

DIGIAMPIETRI, L. A. et al. Combinando workflows e semântica para facilitar o reuso de software. Revista de Informática Teórica e Aplicada: RITA, v. 20, p. 73-89, 2013. Citado 3 vezes nas páginas 16, 24 e 64 .

DIGIAMPIETRI, L. A. et al. An extensible framework for genomic and metagenomic analysis. In: Advances in Bioinformatics and Computational Biology. Springer International Publishing, 2014, (Lecture Notes in Computer Science, v. 8826). p. 1-8. ISBN 978-3-31912417-9. Disponível em: <http://dx.doi.org/10.1007/978-3-319-12418-6_1>. Citado na página 64.

DIGIAMPIETRI, L. A.; PEREZ-ALCAZAR, J. d. J.; MEDEIROS, C. B. An ontology-based framework for bioinformatics workflows. IJBRA, v. 3, n. 3, p. 268-285, 2007. Disponível em: <http://dx.doi.org/10.1504/IJBRA.2007.015003>. Citado na página 24.

DIGIAMPIETRI, L. A.; PEREZ-ALCAZAR, J. d. J.; MEDEIROS, C. B. An ontology-based framework for bioinformatics workflows. International Journal of Bioinformatics Research and Applications, v. 3, n. 3, p. 268-285, 2007. Disponível em: $<$ http://inderscience.metapress.com/content/BH83K31847158824>. Citado na página 24 .

DIGIAMPIETRI, L. A. et al. Uso de Planejamento em Inteligência Artificial para o Desenvolvimento Automático de Software. In: Autonomous Software Systems (AutoSoft 2011). [S.l.: s.n.], 2011. Citado 2 vezes nas páginas 16 e 24.

DORNEMANN, K. et al. Integrating Virtual Execution Environments into Peer-to-Peer Desktop Grids. In: 2012 20th Euromicro International Conference on Parallel, Distributed and Network-based Processing. IEEE, 2012. p. 333-340. ISBN 978-1-4673-0226-5. ISSN 1066-6192. Disponível em: <http://ieeexplore.ieee.org/lpdocs/epic03/wrapper.htm?arnumber $=6169569>$. Citado 2 vezes nas páginas 14 e 20. 
DUAN, K. et al. Composition of engineering web services with universal distributed data-flows framework based on ROA. In: Proceedings of the Third International Workshop on RESTful Design - WS-REST '12. New York, New York, USA: ACM Press, 2012. p. 41. ISBN 9781450311908. Disponível em: <http://dl.acm.org/citation.cfm?id=2307819.2307830>. Citado 4 vezes nas páginas 14, 15, 20 e 21.

JAGADISH, H. VBI-Tree: A Peer-to-Peer Framework for Supporting Multi-Dimensional Indexing Schemes. In: 22nd International Conference on Data Engineering (ICDE'06). IEEE, 2006. p. 34-34. ISBN 0-7695-2570-9. Disponível em: <http://ieeexplore.ieee.org/articleDetails.jsp?arnumber $=1617402>$. Citado na página 28.

KONDO, D. et al. Characterizing resource availability in enterprise desktop grids. Future Generation Computer Systems, v. 23, n. 7, p. 888-903, 2007. ISSN 0167-739X. Disponível em: <http://www.sciencedirect.com/science/article/pii/S0167739X06002111>. Citado na página 14.

KWAN, S. K.; JOGESH, K. M. Bag-of-Tasks applications scheduling on volunteer desktop grids with adaptive information dissemination. In: IEEE Local Computer Network Conference. IEEE, 2010. p. 544-551. ISBN 978-1-4244-8387-7. ISSN 0742-1303. Disponível em: <http://ieeexplore.ieee.org/lpdocs/epic03/wrapper.htm?arnumber $=5735771>$. Citado 3 vezes nas páginas 28, 32 e 33 .

LAGARIAS, J. C. The $3 \mathrm{x}+1$ problem and its generalizations. The American Mathematical Monthly, v. 92, p. 3-23, 1985. Citado na página 49.

LARSON, S. M. et al.Folding@Home and Genome@Home: Using distributed computing to tackle previously intractable problems in computational biology. 2002. Citado na página 20 .

MAJITHIA, S. et al. Triana: a graphical Web service composition and execution toolkit. In: Proceedings. IEEE International Conference on Web Services, 2004. IEEE, 2004. p. 514-521. ISBN 0-7695-2167-3. Disponível em: <http://ieeexplore.ieee.org/lpdocs/epic03/wrapper.htm?arnumber $=1314777>$. Citado na página 14.

MASTROIANNI, C. et al. A scalable super-peer approach for public scientific computation. Future Generation Computer Systems, v. 25, n. 3, p. 213-223, 2009. Disponível em: <http://www.sciencedirect.com/science/article/pii/S0167739X08001209>. Citado 4 vezes nas páginas $28,32,33$ e 34 .

MEDEIROS, C. B. et al. WOODSS and the Web: Annotating and Reusing Scientific Workflows. ACM SIGMOD Record, v. 34, n. 3, p. 18-23, 2005. Citado na página 23.

MEDEIROS, J. W. et al. Scientific workflow systems. NSF Workshop on Workflow and Process Automation: State-of-the-art and Future Directions, 1996. Disponível em: $<$ http://citeseerx.ist.psu.edu/viewdoc/summary?doi=10.1.1.27.6464>. Citado 2 vezes nas páginas 14 e 19.

MURATA, Y. et al. Implementation and evaluation of a distributed and cooperative load-balancing mechanism for dependable volunteer computing. In: 2008 IEEE International Conference on Dependable Systems and Networks With FTCS and 
$D C C$ (DSN). IEEE, 2008. p. 316-325. ISBN 978-1-4244-2397-2. Disponível em: $<$ http://ieeexplore.ieee.org/lpdocs/epic03/wrapper.htm?arnumber $=4630100>$. Citado 2 vezes nas páginas 28 e 32 .

MUTKA, M. W.; LIVNY, M. The available capacity of a privately owned workstation environment. Performance Evaluation, v. 12, n. 4, p. 269-284, 1991. Disponível em: <http://www.sciencedirect.com/science/article/pii/016653169190005N>. Citado na página 14.

PELTZ, C. Web services orchestration and choreography. Computer, v. 36, n. 10, p. 46-52, Oct 2003. ISSN 0018-9162. Citado na página 14.

RIUS, J. et al. Incentive mechanism for scheduling jobs in a peer-to-peer computing system. Simulation Modelling Practice and Theory, v. 25, p. 36-55, 2012. Disponível em: <http://www.sciencedirect.com/science/article/pii/S1569190X12000305>. Citado 4 vezes nas páginas 28, 29, 30 e 32 .

SCIENCETALK e. Desktop grids: Connecting everyone to science. 2011. Citado na página 21.

SEFFINO, L. et al. WOODSS - A Spatial Decision Support System based on Workflows. Decision Support Systems, v. 27, n. 1-2, p. 105-123, 1999. Citado na página 23.

TAYLOR, I. J. et al. Scientific versus Business Workflows. In: Workflows for e-Science: Scientific Workflows for Grids. [S.l.: s.n.], 2007. cap. 2, p. 9-16. Citado na página 19.

Wen Dou et al. A P2P approach for global computing. In: Proceedings International Parallel and Distributed Processing Symposium. IEEE Comput. Soc, 2003. p. 6. ISBN 0-7695-1926-1. ISSN 1530-2075. Disponível em: <http://ieeexplore.ieee.org/lpdocs/epic03/wrapper.htm?arnumber $=1213451>$. Citado 4 vezes nas páginas 28, 29, 32 e 33.

ZHAO, Z.; YANG, F.; XU, Y. PPVC: A P2P volunteer computing system. In: 2009 2nd IEEE International Conference on Computer Science and Information Technology. IEEE, 2009. p. 51-55. ISBN 978-1-4244-4519-6. Disponível em: <http://ieeexplore.ieee.org/lpdocs/epic03/wrapper.htm?arnumber $=5234999>$. Citado 6 vezes nas páginas 14, 28, $29,32,33$ e 34 .

ZHOU, D.; LO, V. WaveGrid: a scalable fast-turnaround heterogeneous peer-based desktop grid system. In: Proceedings 20th IEEE International Parallel \&5 Distributed Processing Symposium. IEEE, 2006. p. 10 pp. ISBN 1-4244-0054-6. Disponível em: $<$ http://ieeexplore.ieee.org/lpdocs/epic03/wrapper.htm?arnumber $=1639267>$. Citado na página 14.

ZUNIGA, J. C. et al. A loosely coupled architecture for automatic composition of web services applications. Int. J. Metadata Semant. Ontologies, v. 9, n. 3, p. 241-251, jul. 2014. ISSN 1744-2621. Citado 2 vezes nas páginas 16 e 24. 